\title{
A Broadening of Prospects \\ Female Progression in Austen and Eliot
}

\author{
By \\ Lydia Verschaffelt
}

\author{
A thesis \\ submitted to Victoria University of Wellington \\ in fulfilment of the requirements for the degree of \\ Master of Arts in English Literature
}

Victoria University of Wellington

2019 


\section{Contents}

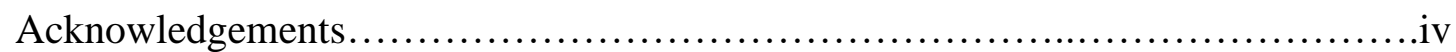

Abstract....................................................................

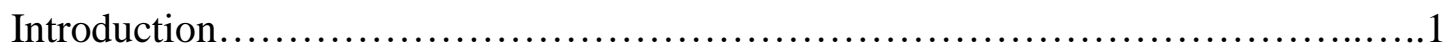

1. Marriage Comes as the End?

The Daughter-Wife Dichotomy and Austen's Subversion of the Marriage Plot in

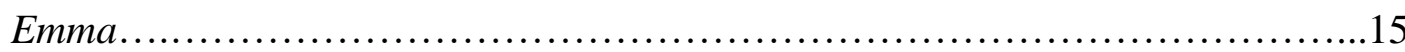

2. Maggie Tulliver and the Backward Flowing Tide

Female Belonging and the Necessity of Return in The Mill on the Floss.

3. Stepping Into the Unknown

Beyond Hearth and Home in Persuasion and Middlemarch.....................64

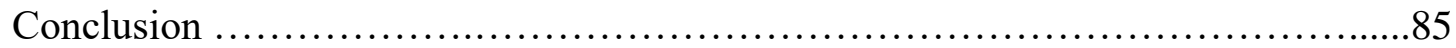

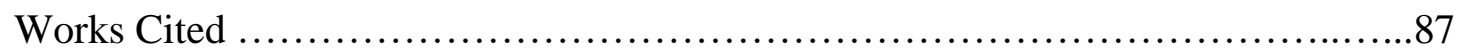




\section{Acknowledgements}

I owe my biggest thanks to my supervisor, Adam Grener, who unfailingly combined intellectual rigour and insight with patience and encouragement.

I am the very grateful recipient of a Master's by Thesis Scholarship, and thank you to Victoria University of Wellington for providing such welcome financial support. Thank you also to the VUW English programme staff for their teaching and guidance, and particularly to Harry Ricketts for his encouragement over the years.

Thank you to my parents for their continued love and support-and whose first response after reading the first chapter was that they were glad I was going to look after them in their old age. They are yet to read the third.

Thank you to family and friends - particularly Sam, Morgan and the girls of vZ804without you it wouldn't have been half as much fun.

And finally, thanks to Fish, for always keeping my head above water. 


\begin{abstract}
Austen and Eliot register the turbulence and transformation of their respective historic moments in the portrayal of a young heroine on the cusp of adulthood with a number of potential paths ahead of her. The heroines, like their societies, are caught between old and new as they seek to acknowledge the ties that bind them to the past and simultaneously create a future of their own. This dilemma reveals the nineteenthcentury novel's concerns of the individual's ability to grow while being enmeshed in a network of relationships, and the place of the past in an increasingly unstable future.

Beginning with Emma (1815) and The Mill on the Floss (1860), and concluding with a comparison of Persuasion (1817) and Middlemarch (1871), this thesis tracks Austen and Eliot's depiction of female development which moves from a focus on the centrality of the childhood home, and in particular the heroine's relationship with her father, to a narrative which ends on a more conscious note of ambiguity and broadening prospects. Emma and Mill both depict heroines who find their future in their past. Emma and Maggie develop and assert their own agency, but their circumstances and experiences of childhood bind them to their site of origin.

Conversely, both Austen and Eliot's later works enact a deliberate loosening of the hold the heroine's childhood has on her, and Anne and Dorothea end up in very different places to where they began. They both reject their position as part of the rural landed gentry to instead gain entry into a more dynamic and inclusive community. This personal transition is accompanied by a more explicit delineation of the evolving socio-political landscape, an increase in the heroine's mobility and fluidity, and an ending that frustrates a sense of stable closure in preference for one of more open possibility. Thus, so far from being read simply as 'marriage plots' Austen and Eliot subversively depict the young woman's changing position and prospects as a matter of national importance.
\end{abstract}




\section{Introduction}

"A son is a son till he takes a wife, a daughter is a daughter all of her life" - Irish Saying

The "modern individual was first and foremost a woman" - Nancy Armstrong, Desire and Domestic Fiction (8)

Time present and time past

Are both perhaps present in time future And time future contained in time past. - T.S. Eliot, “Burnt Norton” (1-3)

At the realisation of snow falling during a social party in Emma (1815), Mr Woodhouse's first response is to cry, "What is to be done, my dear Emma? - what is to be done?" This was "all that he could say for some time" and to "her he looked for comfort" and "assurances of safety" (120). Similarly, in the first flush of the news of his financial ruin, The Mill on the Floss's (1860) Mr Tulliver experiences "a craving which he would not account for to himself, to have Maggie near him-without delay - she must come back by the coach to-morrow" (227). In both novels, the father's visceral need for his daughter's presence in a moment of crisis instigates her immediate devoted return to his side. These two episodes of intense agitation, while of differing severity, exemplify how Emma and Maggie operate as the port in the storm for their fathers. They are the sole person who can materially provide comfort and alter their father's state - they are their fathers' embodiment of home. Yet this complex position of simultaneous power and restriction is inherently one that cannot be sustained by either heroine or narrative. The daughter fulfilling the status of 'home' requires a stagnancy and stillness that is at odds with the nineteenth-century novel's drive for individual growth and fulfilment, the impetus for wider social progression, and the plot's need for variation and resolution. The binding to father, home, and past moulds the heroine's character but also hinders her ability to step forward into her own future. For Susan Stanford Friedman, "Modernity and tradition are relational concepts that modernity produces to cut itself off from the past, to distinguish the 'now' from the 'then"' (156). However, the dependent daughter rejects this linear framework as her 'then' is inherently present in her 'now.' Instead of being 
'cut off,' her childhood and past are bound up in her future due to her continued position in her father's house.

The concept of the heroine being her father's incarnation of 'home' forms part of a larger, well-established literary tradition in which the male hero journeys to discover and define himself, and then returns 'home' - a state of being less defined by a physical space than the form of a waiting and welcoming feminine figure- be it wife, mother or daughter. The immobile woman is the still point of the compass and the pinpoint on the map for him to return to and track his own development againstthe Penelope to his Odysseus. ${ }^{1}$ However, the daughter offers a particularly fraught invocation of the seemingly secure 'home' as she is fundamentally an unstable figure who rejects fixity through her inherent capacity for growth, movement, and the latent potential to create her own home with another.

The daughter's charged and divided dynamic is one with a long-standing historical precedent. The figure of the divided daughter is found in Ancient "Greek mythic thinking, which assigns mobility to the male and stability to the female, who at least symbolically tends the home-fire. Yet this daughter of the oikos is also a potential bride and must move to another household in order to fulfil her destiny" (Lyons 47). Similarly, the King James Bible likens the relationship between humanity and God to that of young bride and bridegroom, calling 'her' to "Hearken, O daughter, and consider, and incline thine ear; forget also thine own people, and thy father's house; So shall the king greatly desire thy beauty: for he is thy Lord; and worship thou him" (Psalm 45:10-11). Both this classical description and theological analogy depict the establishment of the young woman's new union and future being predicated on her physical relocation and distancing from her parents and earlier life. They reveal the implicit tensions of the daughter's position that calls for her rejection of the very past that moulded her-which she was taught to revere and remain loyal to- - so she can step unencumbered into the next stage of her life.

While it may be a longstanding paradigm, the uncertainty of the young woman's fraught and liminal positioning took on a new sense of urgency in the shifting social milieu and turbulence of the nineteenth century. The problem of the

\footnotetext{
${ }^{1}$ Donald J. Greiner claims that in traditional marriage plots "male love guarantees female worth. The issue becomes not quest but confirmation: the hero sallies forth to the wilderness, but the heroine stays behind beside the hearth. Her territory is not the threatening adventure but, rather, the predictable routine" (23).
} 
heroine caught between her past and possible future dominates the nineteenth-century novel. She seeks to acknowledge the ties of family and home while simultaneously creating a fulfilling future of her own. This is a quandary that particularly resonates with nineteenth-century concerns of the individual's ability to grow while being enmeshed in a network of relationships, and the place of the past in an increasingly unstable future. This thesis compares the manner in which Jane Austen and George Eliot, one at the start of the century and the other decades later, both take up this same problem of how the daughter's progress is complicated by her ties to past and home. Neither Austen nor Eliot is content with the daughter being a stagnant and still domestic figure unable to access the realisation of her own aspirations and future. However, both acknowledge the difficulty of her position, especially when her ties to her father and home are not simply ones of duty, but also those of love and belonging. This thesis consequently involves reading female identity and development through both a grounding sense of home and the necessity of change, with the understanding that while 'home' seems comforting in its stability, it is itself dynamic and fluid. I argue that Austen and Eliot's depiction of female progression involves interrogating not only the formation of the individual, but also the formation of the family, society and the novel itself.

Austen and Eliot have been selected as the comparative centre for this study due to the striking manner in which, while they solve this literary and ideological problem differently according to their own time and style, they enact a similar shift in solution from an earlier to a later work. They depict a heroine who symbolically 'tends the home-fire' for the duration of the novel_Emma (1815) and The Mill on the Floss (1860) - and both authors later abandon this formulation in a more political and historicised work to instead represent a heroine who has been deliberately severed from her past to achieve a more uncertain and ambiguous future-Persuasion (1817) and Middlemarch (1871). For Austen and Eliot, therefore, the daughter becomes a rich site to explore and challenge the nineteenth-century novel's ability to depict and define the progress of the female individual and a society on the brink of change, not as one of simple linear teleological progression, but a more nuanced negotiation between past and present. To more holistically encapsulate the scope of this depiction, my thesis reads each text in light of four central aspects: the historical context, reference to the narratological form of the Bildungsroman, the gender dynamics at play, and the negotiation of closure in their controversial endings. In doing so I aim to 
show how Austen and Eliot advocate for a subversion of static structures and a need for more dynamic change, not only for their heroines, but also for the narrative form of the novel and the position of women in their societies.

\section{A Figure Of The Time}

While female protagonists have been frequently read as restricted and constrained by their ties to others and the past, this thesis argues that their very position renders them uniquely placed to register the parameters of their historic moment. Both Austen and Eliot were writing during times of intense social flux in the form of increasing exploration, urbanisation, mechanisation and democratisation. Accordingly, the previously rigid and codified social order was being destabilised as the shape of society adapted and shifted to encompass these significant changes. In her book Mobility and Modernity in Women's Novels, 1850s-1930s, Wendy Parkins examines female mobility in regards to social change, noting that women's "participation in modernity, however, is always framed - and complicated - by a persistent association between women and tradition, the past or nostalgia, as a result of women's historical connection with the domestic sphere" (2). The dependent daughter aptly embodies this principle, being at once a figure of youth and possibility but her position in her father's house, often fulfilling domestic duties, keeps her connected to an earlier way of life. Therefore, while our most persistent image of a character embodying the movement, ambition, and possibility of the nineteenth century is likely an orphaned, mobile male - a Dickensian David or Pip — it is the young daughter, in her position at once bound to the past, while also looking forward, who is perhaps the more apt reflection of the shifting socio-political landscape and conflicting temporal concerns of the period.

Whereas the male protagonist is customarily rendered free of ties to allow him to begin his journey to various locales, searching for a defining vocation, sense of self and place in the world, the female must instead combine her own aspirations and desires with those of the people who surround her. The novels of this period reveal what "it is to be a woman, entangled more inextricably than men are in the meshes of custom" (Duncan 122). The female's position then is not just that of an individual, but also frequently that of the collective in her association with domestic customs and tradition to bring people together. The 'connectivity' of the female becomes increasingly pertinent as the nineteenth century enacts a move from the rural to the 
urban, which in turn requires the individual to be integrated not only into a nuclear family, but also into a wider, and more varied network of relationships. The female already enacts this historical shift, in miniature, in her adhesive role in the family unit and potential to bind a pre-existing family to a new one. Therefore, while feminist criticism has provided indispensable analysis of the power imbalances and restrictions of the heroine's entangled position, I believe it is important to temper this with the acknowledgment that her very connectivity is also a trait to be celebrated. While her familial relationships are often fraught, the heroine's negotiation of them presents just as rich and representative an experience as the hero who leaves for parts unknown. Maggie and Emma's enduring bond with their fathers and paternal homes are consequently expressions, not only of their personal relationships, but also of their societies, which were engaged in a process of transformation while simultaneously looking back to what they perceived as a simpler earlier time. Mark Bevir notes that in their time of intense dynamic change, the Victorians were torn between developmental historicism and historical sentimentality (13). They were caught between notions of linear progress and development, and "nostalgia for personal and social innocence" leading to the desire "to preserve and venerate aspects of the past" (13). The dependent daughter connected to both her father and the future is thus the ideal literary figure to embody this tension that defined a society.

\section{Beyond the Bildungsroman}

The daughter's entangled position and predicament between past and future makes her a complicated and uneasy figure to read in regards to the Bildungsroman form. Widely regarded as beginning with Goethe's Wilhelm Meister's Apprenticeship (1795), the Bildungsroman or the 'novel of formation' is, at its most fundamental level, the story of a youth's development until they reach a point of accepted vocation and stable maturation sufficient to become an active and integrated member of their society. It was a narrative structure particularly popular with the Victorian realists, as it presented a clear framework based on principles of determinism and growth to track the complex relationship between the individual and society (Golban $\mathrm{x}$ ). The Bildungsroman provides a sound standpoint to view narratives of youth and growth; however, in this thesis it is a productive reference point rather than an underlying principle due to its linear teleological nature and suppositions of stability. By its very nature, the Bildungsroman presupposes a final end point to an individual's 
development and a stable society for that individual to become part of. Conversely, my analysis highlights the limits of the paradigm of a secure and fixed home or society and instead proposes that the daughter of nineteenth-century fiction is a figure of continuing dynamism and consequently uniquely suited to depicting wider societal change and uncertainty.

While my thesis is not centrally concerned with the Bildungsroman itself, much of the critical discussion surrounding it is constructive in clarifying the manner in which Austen and Eliot portray the progression of their young female protagonists. For instance, Franco Moretti and Jerome Buckley in their seminal texts on the Bildungsroman, The Way of the World (2000) and Season of Youth (1974) respectively, provide perceptive analysis on the nature of youth in narrative. At the same time, however, their categorizing principles narrow the parameters of the genre, rendering it less relevant to a discussion of the daughter's fluid position. Moretti proposes that youth is 'modernity's 'essence,' the sign of a world that seeks its meaning in the future rather than in the past" (5). The youth's ability, and indeed need, to be a vessel of modernity and possibility is clearly signalled, but the focus on the future at the exclusion of the past does not accommodate the dependent daughter who does not have such a luxury, being instead entangled and caught between the two. This difficulty is also registered through its omission in Buckley's claim that the protagonist in a Bildungsroman is frequently "orphaned or at least fatherless" (19). It is the loss or absence of the father that "usually symbolizes or parallels a loss of faith in the values of the hero's home and family" leading to their abandonment of the home for sites unknown and thus providing the impetus for their journey of development (Buckley 19). In Emma and The Mill on the Floss, instead of representing absent fathers, Austen and Eliot depict two very present and influential ones and ask if the heroine can both grow and keep her faith in home intact without being removed from it. It becomes readily apparent that the tensions arising from these ideological and theoretical formulations are gendered. The recognition of this gendered dynamic led to the coinage and delineation of the term 'female Bildungsroman' by feminist critics in the 1970s to analyse how women writers and characters "represented the suppression and defeat of female autonomy, creativity, and maturity by patriarchal gender norms" (Lazzaro-Weis 14).

The female Bildungsroman reclaimed numerous female authored and centric texts and allowed them entry into a form from which they had been previously 
excluded, but in doing so also propagated around them a language of female guilt, limitation and regression. The 1970's-90's saw a plethora of seminal critical feminist Bildungsroman texts from scholars such as Rachel DuPlessis, Marianne Hirsch, Esther Kleinbord, and Laura Sue Fuderer, who brought the treatment and depiction of the female protagonist to the forefront of eighteenth- and nineteenth-century literary criticism. Whereas Emma and The Mill on the Floss had previously been on the margins of Bildungsroman criticism due to the inability of their female protagonists to meet all the requirements frequently fulfilled by male ones, they were now firmly at the apex of their own subset of the genre. ${ }^{2}$ The thrust of criticism on the female Bildungsroman predominantly centred on the narrow nature of the heroine's ending which fluctuated between two options: approbation in the form of "successful courtship, marriage," or judgement due to "sexual and social failure" resulting in "death" (DuPlessis, "Ending" 282). Many considered these one and the same, as both resulted in the heroine's loss of autonomy and narrative erasure. The understandable annoyance at the heroine's lack of prospects at the novel's close led to the cultivation of a language of restriction. Annis Pratt famously defined the female Bildungsroman as a model in which "growing up" for the young woman inherently meant "growing down," as she was subjected to a repression of the very traits which made her a spirited and subversive protagonist to be reduced to a socially acceptable and biddable 'child-like' wife (14). If the heroine did achieve an ending beyond death and marriage, she had to engage in a process of "shedding" which required ridding herself "of excess baggage" and her accompanying guilt, to focus on her own development rather than tending to the needs of those around her (Labovitz 253).

This thesis seeks to challenge the idea that the heroine's past and family is inherently a burden that she must overcome, arguing it is instead a crucial aspect in her formation. I also contend that, against the Bildungsroman model, Austen and Eliot's endings depict continuing female development rather than linear growth ending in submissive stagnation. John Stuart Mill in his 'The Subjection of Women' (1869) refreshingly rallies for the rights of women. He also claims that "Human

\footnotetext{
${ }^{2}$ Buckley does not consider Emma a Bildungsroman, as it does not meet a sufficient number of his criteria for the form, which are: "childhood, the conflict of generations, provinciality, the larger society, self-education, alienation, ordeal by love, the search for a vocation and a working philosophy" (18). Interestingly, Jane Eyre (1847) fulfills these requirements, as her orphaned status and lower social status render her a more mobile figure, who must find a vocation to support herself.
} 
beings are no longer born to their place in life, and chained down by an inexorable bond to the place they are born to, but are free to employ their faculties, and such favourable chances as offer, to achieve the lot which may appear to them most desirable" (29-30). The first two chapters of this thesis argue that the heroine is not unchained, but that her chains may forge a sense of belonging and connection, rather than limitation. The third chapter moves to a position closer to Mill's formulation, as the heroine removes herself from the place in life to which she was born and operates separate to these ties.

\section{The Openness of Closure}

The Bildungsroman's emphasis on "teleological rhetoric - the meaning of events" lying "in their finality" encapsulates a broader concern of the nineteenth-century novel, and narratology as a whole-namely that a story cannot continue indefinitely but must come to an end (Moretti 7-8). The serialisation of Victorian texts also deliberately enhanced and prolonged readers' suspense, placing even more pressure on the narrative to deliver a sufficient sense of closure. In a letter to her publisher John Blackwood, Eliot wrote, "Conclusions are the weak points of most authors, but some of the fault lies in the very nature of the conclusion, which is at best a negation" (Letters 443). This observation speaks to the difficulty of the novel's conclusion to sufficiently address all strands of the narrative, without rendering any hollow or meaningless, while also satisfying the reader's expectations. Her comment is also telling given that many of her contemporary readers and later critics criticized the ending of Eliot's novels for the sense of disappointment and deflation they induced. ${ }^{3}$ D. A. Miller goes even further than Eliot's 'negation' claiming that although closure "implies resolution," it can never truly deliver it and is instead "an act of "makebelieve" (275). What becomes readily apparent through these critical views is that while an ending may seem natural, in reality it is a difficult prospect to obtain.

While resolution is only fantasy for Miller, for many readers the novel's end is inherently weighted with significance in that it confers retrospective meaning to the

\footnotetext{
${ }^{3}$ Jenni Calder posits: "Sadly, and it is a radical criticism of George Eliot, she does not commit herself fully to the energies and aspirations she lets loose in these women. Does she not cheat them, and cheat us, ultimately, in allowing them so little? Does she not excite our interest through the breadth and challenge of the implications of her fictions, and then deftly dam up and fence round the momentum she has powerfully created?" (158)
} 
text as a whole. In Closure in the Novel, Marianna Torgovnick posits that it is this very aspect of endings we value "because the retrospective patterning used to make sense of texts corresponds to one process used to make sense of life: the process of looking back over events and interpreting them in light of "how things turned out"' (5). ${ }^{4}$ The backwards narrative gaze of closure echoes the Victorian's espousal of 'developmental historicism' for its ability to confer meaning and order on the past through recasting it as part of a linear sequence of events which culminate in the present moment. It is easy to see how Austen's readers in the midst of the Napoleonic Wars, and Eliot's amongst the turbulence of radical social and political reforms, found comfort in narratives which conferred a sense of comfort and stability at their close. Nineteenth-century novels with female protagonists were, and still are, frequently viewed solely as marriage plots and their inevitable endings offer the peak of stability -"the definitive and classifying act par excellence" (Moretti 7). Whether the heroine transitioned from daughter to wife in triumphantly reaching the altar at the novel's end or failed to do so provided a simplistic binary to ensure closure and judge the success of her development through this final act. However, as demonstrated in the criticism of female Bildungsromane, the sense of final stability so comforting for some readers, frequently diminished and limited the value of the protagonist's growth for others. The relinquishing of dynamism and possibility for the sake of narrative closure and decisiveness undermined the journey which preceded it.

While all of the four central texts of this thesis do end with the protagonist's marriage, or in one instance death, I aim to bring to the fore the tangible sense of possibility and openness that Austen and Eliot generate in their novels' endings. The most positive interpretations of these endings are usually ones of tempered optimism or compromise. For instance, Lorna Ellis views the conclusions of female Bildungsromane, such as Jane Eyre and Emma as "ambiguous precisely because the female development portrayed is double-sided - both conservative and subversive," as the heroines marry but also develop their ability to "manipulate societal expectations" (34). Similarly, though less ambivalently than Ellis, I read the endings of these novels as manipulations of traditional literary conventions, such as the concluding marriage, and a decisive expression of the heroine's power through her

\footnotetext{
${ }^{4}$ Frank Kermode similarly explains in his The Sense of an Ending that "[w]e can perceive a duration only when it is organized ... we use fictions to enable the end to confer organization and form on the temporal structure" (45).
} 
continuing progression and influence. Furthermore, I propose that in their rejection of a sense of definitive closure of both the narrative and heroine's development, Austen and Eliot cultivate an affect of uncertainty, possibility and continuity that looks forward to the work of modernist and female authors such as Virginia Woolf. Christiane Makward defines "l'écriture feminine" as "open, non-linear, unfinished, fluid" (96) and Rachel DuPlessis similarly describes it as "fluid, non-linear, decentralized, multi-voiced, non-hierarchic" (Etruscans 244). ${ }^{5}$ While Austen and Eliot are both clearly writing within the conventions of their time, I posit that their subversion of these conventions, such as their rejection of a linear depiction of development and sense of stability at their novels' ends, reveals burgeoning aspects of a female literary aesthetic which will be continued and further experimented with by later authors. Their endings are thus a negotiation between the dictates of the time, both social and literary, and the possibilities beyond them.

\section{The Positioning of the Heroine}

The complexities of female autonomy, movement and marriage is at the heart of the dependent daughter's position. Sandra Gilbert and Susan Gubar note that the various visits and social calls of Austen's heroines remind us "that women are dependent on fathers or brothers for even this most limited form of movement" (Gilbert and Gubar 125). The issue of being stranded awaiting male assistance is a reality that repeatedly occurs in Austen's personal correspondence and is exemplified in a 1796 letter to her sister Cassandra. She writes, "My Father will be so good as to fetch home his prodigal Daughter from Town, I hope unless he wishes me to walk the Hospitals, Enter at the Temple, or mount the Guard at St James" (Letters 12). While playful in her tone, Austen inherently links the limitations of female mobility and dependence with their lack of vocational prospects. To be allowed free movement opens up a politicised space of possibility where she could be studying medicine, the bar, or even become a soldier. Instead, in Austen and Eliot's social milieu and that of their heroines, "the acceptance or refusal of a marriage proposal was the chief place where a gentlewoman had the opportunity to make a free decision" (J. Hillis Miller 151). And yet as Mrs Cadwallader wryly notes in Middlemarch, “A woman's choice usually

\footnotetext{
${ }^{5}$ Ann Rosalind Jones describes "a set of stylistic and formal tendencies widely recognized in l'écriture feminine: double or multiple voices, broken syntax, repetitive or cumulative rather than linear structure, open endings" (88).
} 
means taking the only man she can get" (506). While Austen and Eliot depict marriage differently, neither views it as the culmination of a protagonist's character. Both emphasise the importance of female mobility, often through depicting the limitations imposed on it. Austen and Eliot show their heroine's ability to evolve without necessarily having the luxury a male protagonist might have in leaving the home.

Part of the work of this thesis is to reclaim the heroine's connection to the past and in particular the figure of the father. While the lack of mothers in the nineteenthcentury novel and the effect their absence has on the young heroine is a welldocumented phenomenon, less critical attention has been given to the figure of the 'affectionate father'. ${ }^{6}$ I seek to address the trend, which has emerged of vilifying the father as the figurehead of patriarchal oppression, and instead argue that in a number of texts, the author takes great pains to emphasise how the heroine's identity is crucially formed by their relationship. The recurrence of the dynamic of a close, almost symbiotic bond, between a father and daughter in prominent nineteenthcentury texts, attests to the manner in which the relationship clearly had traction in the popular imagination. One thinks of Scott's Waverley (1814), Dickens' David Copperfield (1849), Gaskell's Wives and Daughters (1864), Trollope's Can You Forgive Her? (1864), and Hardy's The Woodlanders (1866). In all of these texts the father is vital to the daughter's development. Often his deficiencies call forth an answering competency and intelligence in her, which plays a prominent role in making her the compelling heroine she is. ${ }^{7}$ However, the "socially institutionalized by-product of the father-daughter dynamic that became attached to the ideal of femininity in the nineteenth century was the arrested development of the daughter" (Cohen 1993). The affectionate nature of the father is consequently crucial in the first two texts of this thesis, as he further complicates the heroine's mobility in that she does not necessarily wish to leave home or him. In Emma and The Mill on the Floss,

\footnotetext{
${ }^{6}$ See Carolyn Dever's Death and the Mother from Dickens to Freud: Victorian Fiction and the Anxiety of Origins (1998), Maria Westkott's "Mothers and Daughters in the World of the Father" (1978), and Barbara Z. Thaden's The Maternal Voice in Victorian Fiction: Rewriting the Patriarchal Family (2013).

${ }^{7}$ Catherine England observes that in "many cases, the heroines of marriage plots have fathers who are unable to protect them fully from the consequences of their social missteps. The ineffectuality of the father allows the hero the opportunity to seize the post of protective father and thus grant the heroine a new family that restores and often increases her social capital" (121).
} 
Austen and Eliot are thus working in this wider pattern of the nineteenth-century father-daughter literary dynamic, but both subvert the conventional assumption that the daughter inevitably will and should leave her father for a future husband. In doing so, they complicate the heroine's temporal and spatial development from past to future, from childhood to marital home.

The first chapter of this thesis establishes the daughter's dilemma of being torn between past and present with Austen's Emma - an eponymous heroine firmly ensconced in the perimeter of shrubberies her paternal house affords. It sets up the parameters of the heroine's development being triangulated between her close relationship with her father, the power and belonging she derives from presiding over her home, and the necessary change which must drive the plot and alter her perspective. The chapter centres on the controversial ending of Emma, which sees the protagonist remaining at Hartfield with both husband and father, reading it not as a restrictive and claustrophobic conclusion but instead Austen's sly subversion of the marriage plot to allow her protagonist both her past and future. In Emma, I argue that Austen is calling for the acknowledgment that sometimes the bravest and best option for the heroine is not venturing into the unknown and abandoning her ties to the past, but instead staying exactly where she is while still evolving and adapting to the shifts of her position and the society around her. Austen suggests that the decision to stay does not constitute a failure of development, but rather, more accurately reflects the entangled position of many women.

Whereas Emma depicts its heroine progressing while remaining in the same physical location, Chapter Two focuses on a protagonist who is defined by her movement 'back' to her home and father. The Mill on the Floss explores what happens when the heroine is bound by her ties to the past but cannot be sustained by them. Eliot is concerned with the heroine's connection to family when it is at once connected to, but also at the cost of, her own desires and evolution. Throughout the novel Maggie enacts a cyclical pattern of return to the mill, and inherently her father and past, thus refusing a linear trajectory of development from daughter to wife. While marriage was part of Austen's solution to the dependent daughter's fraught position, for Eliot in Mill it is no longer a viable option for Maggie. Chapter Two shows how the novel plays out various potential narratives for the heroine in the form of a renunciation, vocation, or marriage plot. Each of these plots would have endowed Maggie with a socially sanctioned, but personally unfulfilling future, and they are all 
consequently rejected in preference to her union with her past and the Floss. This chapter also explicitly links Maggie's temporal choice to that of her society, in her association with the mill and thus a form of power and way of life that was becoming increasingly redundant.

Chapter Three enacts a shift from the previous chapters, both in its own form and the subject matter of Austen and Eliot's approach to the daughter's position in their later works. In a comparative study of Persuasion and Middlemarch, the final chapter tracks Austen and Eliot's depiction of female development, which has moved from a focus on the centrality of the childhood home, and in particular the heroine's relationship with her father, to a narrative that resolutely hollows out these aspects of the heroine's past and renders her a much more mobile figure. While Emma and Maggie grow and assert their own agency, their circumstances and experiences of childhood bind them to their site of origin. Conversely, both Anne and Dorothea end up in very different places to where they began. The father is no longer a significant tie and both heroines reject their position as part of the rural landed gentry to instead gain entry into a more dynamic, progressive and inclusive metropolitan community. The changing and shifting social dynamics that were becoming apparent in Emma and Mill are brought to the fore in Persuasion and Middlemarch, where they are played out on a much wider social and political stage than in the earlier novels. Through their negation of childhood and an affectionate paternal figure, the later novels emphasise the importance of these elements in their absence, which also registers a suggestion of nostalgia for an earlier time. In these later novels, the need for a more decisive change to the shape of society led Austen and Eliot to break the heroine's ties to the past to increase her mobility and fluidity and provide her with a conclusion that ends on a much more ambiguous note of uncertainty and dynamism.

The thesis as a whole works to highlight the unique position of the nineteenthcentury heroine at the intersection of various dichotomies - that of the individual and the collective, the personal and the political, and the past and the future. In their rejection of static forms and linear development, Austen and Eliot embrace an ethos of continuance - a broadening of prospects and a depiction of female progression that is not bound by fixed parameters and restrictions. In the epilogue of her 2018 autobiography, Becoming, Michelle Obama writes, "For me, becoming isn't about arriving somewhere or achieving a certain aim. I see it instead as forward motion, a means of evolving, a way to reach continuously toward a better self. The journey 
doesn't end" (419). Her language of fluidity and progression reclaims and calls forth a female aesthetic that we can see being developed and advocated for in the work of Austen and Eliot 200 years prior. 


\title{
Marriage Comes As The End? \\ The Daughter-Wife Dichotomy and Austen's Subversion of the Marriage Plot in Emma
}

\begin{abstract}
"What the novels helped to reinforce was the sense that [marriage] was the most important decision, really the only decision of any significance, that a daughter would ever have the chance to take; and that the success or failure of that decision was intimately bound up with the relationship which she had with her father." - Caroline Gonda, Reading Daughter's Fictions (37)

"I believe few married women are half as much mistress of their husband's house as I am of Hartfield; and never, never could I expect to be so truly beloved and important; so always first and always right in any man's eyes as I am in my father's."

- Emma (82)
\end{abstract}

At first glance it may seem odd to begin a thesis on broadening female prospects with a text whose heroine is as firmly enmeshed in her father's home at the novel's end as she was at the start. Emma herself expresses complacency in her position stating, "I cannot really change for the better" as "I am sure I should be a fool to change such a situation as mine" (82). However, it is precisely this seemingly stationary dynamic of the daughter who continues to 'tend the home fire' that Austen utilises in Emma to reject linear temporal, spatial, and developmental paradigms and in doing so, illustrate how drastic individual change can occur without familial abandonment or geographic relocation. Emma matures and grows not through a journey to various locales and unfamiliar communities, as the Bildungsroman model would necessitate, but within the bounds of her familiar Highbury, and for the most part, the restricted shrubberies of Hartfield. She also remains tied to her father, even once married, breaking the traditional marriage plot convention of the heroine transitioning from daughter to wife. Instead of reading this controversial ending at Hartfield with both her father and husband as a dynamic of stagnation and regression, this chapter will argue that it instead allows Emma a stable sense of home, while also providing variation and the prospect of continuing growth. Thus, through her subversion of linear development and the marriage plot form, Austen presents a heroine with whom everything has changed, despite her situation remaining the same. 
I suggest that we need to approach Emma with a 'double vision' that simultaneously views the novel as the marriage plot it undoubtedly is, while also encompassing the manner in which Austen subverts the form and interrogates the practice of defining female identity predominantly through marriage. ${ }^{8}$ Wayne $\mathrm{C}$. Booth suggests that Emma in particular amongst Austen's oeuvre, "works hard to alert the careful reader to the need for double vision - a combination of joyful credulity about the love plot and shrewd sophistication about the characters of men and women" (432). In attempting to account for Austen's enduring appeal, critics have often pointed to her ability to deftly satisfy, and indeed establish, many of the conventions of the romance genre, while simultaneously achieving something more critical and complex. For instance, Emma's own initial refusal to see herself in a marriage plot - "I am not only, not going to be married, at present, but have very little intention of every marrying at all"-itself plays into 'the lady doth protest too much' romance trope, while concurrently pointing to the narrowness of such a position if a character is to be viewed solely in such terms (82). Emma also reveals her awareness of this limitation as she attempts to separate her person from her perceived 'marriageability'. Paula Cohen argues this tension of self-definition is at the structural heart of the marriage plot. She calls for a redefinition of the form in light of the fact that, while it places primary importance on the concluding marriage to classify heroines, its very place at the end of the narrative means they are predominantly operating as "daughters" and are "only potentially or fleetingly wives or mothers" (26). Austen addresses this simplistic binary of daughter or wife in Emma's controversial conclusion, which sees the heroine refuse to abandon one role for another and therefore escape being categorically defined by either.

Emma's development, embrace of change and creation of a less easily classified and demarcated identity mirrors the wider transformation occurring across Highbury society. Austen's novels, particularly Emma, are frequently viewed as quaint, backward-gazing depictions that champion an earlier conservative and aristocratic way of life while ignoring the socio-political turbulence of the early

\footnotetext{
${ }^{8}$ Sally Livingston argues that "[b]y the eighteenth century" the "gradual change in women's rights places marriage in a prominent position in female-authored narratives. Thus, although Frances Burney, Jane Austen, and George Eliot find ways to subvert the marriage plot, the device drives their narratives" (2)
} 
1800s. ${ }^{9}$ When Emma was being written in 1814, Britain was in a state of intense social upheaval and unrest. An emerging middle class was growing in wealth and power and consequently complicating established class distinctions of status and identity. More viscerally, the Napoleonic Wars were continuing to cause devastating loss of life, disillusionment, and debilitating national debt. While Austen engages with the political situation more directly in Persuasion, Emma is also intensely alert to the necessity of change and the turbulence of the time, but enacts it on a smaller and more recognisable stage. ${ }^{10}$ Instead of placing her stories on the French battlefield or in the House of Commons, Austen's sallies and skirmishes occur in the drawing rooms and parlours of "3 or 4 Families in a Country Village" (Letters 287). And subtle changes are occurring within and without these spaces to disrupt Highbury's veneer of stability and stolidness - gypsies are encroaching on estates, poultry houses are being robbed, and the Coles, Perrys and Martins, who were once defined and limited by their class, are beginning to rise. While these alterations may seem comic in their minuteness or merely inventions to facilitate the plot, they combine to create a sense of instability, increasing movement, and the slow awakening of a new dynamic and less easily codified order.

While Emma represents an understated, yet undeniable, sense of forward progress in Highbury's emerging mobile middle class, it also tempers this with a commitment to the past as well as the future in the continued presence of $\mathrm{Mr}$ Woodhouse. In placing more emphasis on Emma's role as a daughter, my argument brings Mr Woodhouse to the fore, an unfamiliar place for him in Austen scholarship. Moving Mr Woodhouse to the centre of Emma allows us to see how Austen utilises him to not only interrogate the construction of female identity through marriage, but to also demonstrate the novel's integrated temporal ideology in the face of wider societal transformation. So far from abandoning those who belong to an earlier time,

\footnotetext{
${ }^{9}$ William H. Galperin notes that "the historical way with Austen has almost always been to stress the conservative, largely regulatory work of her fictions, over and against any other prospects they may entertain" (1). See also Alistair Duckworth's The Improvement of the Estate (1971).

${ }^{10}$ David Monaghan explains: "Jane Austen's decision to deal with the minutiae of her characters' social lives" is not a concession and would "not have seemed to her contemporaries to reflect any intention of escaping social reality. On the contrary, they would have recognised that she was directly encountering the moral questions that had to be answered if a society based on a code of duty and obligation was to flourish" (3).
} 
the novel makes a concentrated effort to depict the importance of valuing the older generation through characters' interactions with Miss Bates and $\mathrm{Mr}$ Woodhouse. $\mathrm{Mr}$ Woodhouse himself is a figure diametrically opposed to change in any form, no matter how minute, and his prominent presence at Emma's conclusion reveals the intensity of the novel's ideology of honouring and including the past in the future's formation. Before turning to Mr Woodhouse, this chapter first shows how Emma's development is set off against the other women of the novel whose plots show how marriage is often a welcomed source of stability and provision for the unattached female. The chapter then moves to a scrutiny of Emma's position at Hartfield, entwined with her father and the simultaneous power and restriction which this state affords. Finally, we turn to Emma's controversial end at Hartfield with both her husband and father to examine how it provides closure but also creates a sense of prospects opening out for the her.

\section{Marriage as Identity \\ The Other Women Of Emma}

Emma not only concludes with a wedding, but also begins with one. Miss Taylor's nuptials in the novel's opening pages announce that matrimony is not simply a narrative finish line, but an institution at the heart of the text. While this may seem a fundamental tenet of an Austen novel, Emma - more so than any of her other worksrepresents the reverberations marriage has, not only in altering the formation of families and communities, but also in the creation of a division between a woman's past and future self. For instance, whereas Pride and Prejudice famously begins with the supposition of the desirability of marriage-"It is a truth universally acknowledged, that a single man in possession of a good fortune, must be in want of a wife"-like most marriage plots, it takes the length of the novel to enact this truth and therefore as Cohen notes, depicts daughters rather than wives (1). Conversely, the marriage of Miss Taylor in the first chapter, and the introduction of the newly wedded Mrs Elton that dominates Volume II, reveal the implications of life after the wedding for a female's identity, even before the engagements of Jane Fairfax, Harriet Smith, and finally the heroine herself occur in the more traditional space of the final chapters. Thus, instead of a wedding providing a sense of teleological closure at the novel's end, every stage of the narrative announces marriage to be the principal and most prolific source of change and definition - both for the individual and the community. 
Austen foregrounds the complexity of Emma's development and marriage against the backdrop of the other marriages in the novel. It is consequently productive to first examine the depiction of these other women's experiences, to which Emma provides the exception. In striking contrast to Emma-Miss Taylor, Mrs Elton, Harriet and Jane are all orphans, or at least operate as such throughout the text. For instance, while Harriet has a living father, he deliberately remains anonymous given her illegitimate status, and no mention is ever made of Miss Taylor's family. The lack of a father renders these women's states precarious and unprotected, and means they must make their own way in the world with uncertain assistance from wider family or friends. Unmarried women are poised in a liminal space between being defined by their fathers' position and familial connections, and their potential husbands'. However, these women without a father, immediate family, or an influential last name like Woodhouse or Knightley to aid them, inhabit an even more nebulous and uncertain space. Consequently, in taking their husband's name and being enveloped by the protection and status of his familial identity, marriage provides them with a secure and elevated role in society.

Without an affluent family or even a permanent home, the other women of Emma must construct an identity predicated on a system of social influence, rather than inherited physical space. Viewed in this light, Mrs Elton's smug boasting of her sister's success in being "very well married, to a gentleman in a great way, near Bristol, who kept two carriages," while still pompous, reveals an unsettling desperation in attempting to bolster and fashion her own identity through her sister's marriage (172). Her repeated references to Selena, Mr Suckling, and their countryseat of Maple Grove, are attempts to attach herself to the language and spaces of the landed gentry to which she aspires. Her bragging also speaks to an embarrassment about her unconnected past as Miss Augusta Hawkins, which Emma rather cuttingly delineates as bringing "no name, no blood, no alliance" to her marriage or Highbury (172). Austen's most ludicrous characters are frequently those obsessed with influence and rank, and she reserves a particular irony and critical treatment for women who cultivate a haughty grandeur and self-importance predicated on family name, particularly their husbands'. Two such women are Pride and Prejudice's Lady Catherine de Bourgh and Emma's Mrs Churchill. Both are tyrannical and full of ancestral "pride and importance" despite only being a de Bourgh or Churchill by marriage (16). 
The novel begins at a moment of flux and transition in Miss Taylor's wedding. Pam Morris notes that Emma "is a novel that proclaims, from its very first page, the inevitability of change" and this "process is enacted as a shift away from the settled order of inherited place to the motility of social space" (83). Miss Taylor's transition from governess to wife of a land-owning gentleman establishes a model of upward mobility through marriage which will be followed later by Jane and Harriet. Her marriage also presents the dichotomy of a married woman being at once exactly who she was and yet inherently altered through being both 'Poor Miss Taylor' and 'Mrs Weston'. While Mrs Weston herself suffers no crisis of identity and seems content in her new life of prominence and security, her absence casts a shadow at Hartfield. Mr Woodhouse's constant refrain of 'Poor Miss Taylor' is a comic expression of his inability to accept change, but also a persistent reminder that Mrs Weston no longer functions in the same role and identity she once did. ${ }^{11}$ Instead of being defined as Emma's governess and caring custodian of the Woodhouse family, her strongest ties of love and duty are now to Mr Weston. Emma "was aware that great must be the difference between a Mrs Weston, only half a mile from them, and a Miss Taylor in the house" (8). The memory of 'Miss Taylor' at Hartfield continues in the minds of Emma and Mr Woodhouse, while being fused with the reality of Mrs Weston at Randalls. Perhaps the most telling indication of this crisis of identity is the manner in which Miss Taylor is most frequently referred to by her maiden name in the critical discourse on Emma, despite being Mrs Weston for the entirety of the novel. Scholars seem to concur with Emma, whose consciousness so intensely governs the text, that her friend remains most truly identified as 'Miss Taylor'. The novel's inherent operation on both the level of marriage plot and a subversion of it is consequently reflected in the continuing inter- and extra-textual life of 'Miss Taylor.'

Enacting a parallel plot to Miss Taylor, Jane Fairfax's trajectory is paradigmatic of the Bildungsroman. She trades one form of indeterminacy for another in her initial orphaned status and later secret engagement with Frank Churchill, and after many tribulations is eventually 'rewarded' with the stability of marriage and the

\footnotetext{
${ }^{11}$ The division between a past and present identity and the female Bildungsroman concept of 'shedding' can be seen in Mrs Elton's diatribe on friends who have given up music since becoming married. There is an inherent sense of something lost, even as she uses it to lord her married state over Emma: "And the same may be said of Mrs. Jeffereys - Clara Partridge, that was - and of the two Milmans, now Mrs. Bird and Mrs. James Cooper; and of more than I can enumerate" (258)
} 
prospect of becoming the next Mrs Churchill. Jane teeters between the glamorous and stimulating world of London, and the sleepy and straitened circumstances of Highbury. Emma chastises Frank and says of Jane, "You forget how much she belongs to Highbury" (189). However, while her aunt may do her utmost to keep Jane at the forefront of every inhabitant of Highbury's mind, she belongs there only in part, just as she only belongs in part with the Campbells. This division is further complicated by the understanding that she will soon no longer inhabit either space but must instead sell her "human intellect" as a governess (279). She is oppressed with "the drawback of the future, the sobering suggesting of her own good understanding to remind her that all this might soon be over" (154). While this phrase describes her time growing up with the Campbells, it is also an apposite representation of her engagement to Frank, which given its secrecy and his machinations, also renders her future shadowy and uncertain. However, the death of Mrs Churchill allows Jane and Frank to wed, which also emphasises the marginal status of women in that one must abdicate their position for another to succeed to it.

Like a traditional marriage plot, Jane's union to the man she loves and prospective relocation to Enscombe signals the closure of her story as she now has both husband and home - a stable identity and a place to completely belong. Jane tells Emma that the arrangements for her and Frank to live at Enscombe are completely “settled" (430). The use of 'settled' here echoes how Mrs Weston is now "settled in a home of her own" and "secure of a comfortable provision" (13). ${ }^{12}$ Miss Taylor and Jane have little compunction leaving behind their past lives and maiden names for the future of security and provision which their new marriage and titles entail. 'Settled' and 'secure' register that for both women what was once precarious has now been solidified. While she provides a more controversial and subversive ending for Emma, in the plots of the other women of the novel Austen is pragmatic in depicting the vulnerabilities of being an unattached female and the manner in which marriage can provide welcomed security, protection, and self-definition.

\section{Reading Emma in Relation to Mr Woodhouse}

In keeping with the novel's requirement for a double vision, Emma has the distinction of being one of the most divisive heroines of nineteenth-century literature. Austen

\footnotetext{
${ }^{12}$ Harriet's union to Robert Martin will similarly provide her with "security, stability, and improvement" (451)
} 
recorded her acquaintances' initial reactions to her work and she writes of Emma that a Mr. B. Lefroy "Did not like the Heroine so well as any of the others," but a Mrs. B. Lefroy "Preferred Emma herself to all the heroines" ("Opinions" 60). While this is perhaps most telling as a glimpse into Mr and Mrs Lefroy's relationship, it is also more widely representative of the way in which Emma staunchly and emotively divides her readership. She incites reactions of both irritation at her highhanded manipulation and self-delusion, and approval, particularly by feminist scholars, for her embodiment of female determination and capability. Both of these opinions stem from Austen's creation of a heroine whose sheer strength of personality is derived, in contrast to the other young women of the novel, from a situation defined by a surplus of security, stability and sense of self.

All that was nebulous and indistinct for the other women is solidified in Emma's position to the point of excess. Not only does she have a loving father, a home to belong to and an already privileged and defined social position, but she also "seemed to unite some of the best blessings of existence" and has lived "with very little to distress or vex her" (7). Consequently, whereas marriage for the other women of the novel is a desirable conduit to provide an established identity and stable role in society, Emma requires no such security. Moreover, her relationship with her indulgent father endows her with a degree of power and influence highly unusual for a young unmarried woman. However, the novel also encourages us to see the subtler pressures and difficulties Emma's position with Mr Woodhouse places on her, and the way in which these set the parameters of both her development and her relationship towards marriage. It is her role as a loving and dutiful daughter that leads her to reject the impetus of the marriage plot and declare, "Marriage in fact, would not do for her" (390). In reading Emma in regards to Mr Woodhouse, we see how she must inherently change her situation both for the progression of the plot and her character, while also remaining partially tethered to him and therefore the past.

Emma's position at Hartfield with Mr Woodhouse is one of subservience, yet superiority - of freedom, yet restriction. Mr Woodhouse is often swept aside as simply a comical character; however, he is fundamental to the construction of Emma's identity and the functioning of her mobility. We find Emma at the novel's start in a position of unusual influence. Her mother's death and father's inadequacy have led her to become mistress of the house at a very young age, and to manage the role with impressive maturity and efficiency. As Mrs Weston notes, she is 
"accountable to nobody but her father," and given his complete adoration and indulgence, this essentially reads that she is accountable only to her own wishes and whims (39). Walter Scott, in his highly influential 1815 review of the novel, began the critical tradition of referring to Emma as a royal personage-_"Miss Woodhouse walks forth, the princess paramount, superior to all" (69). In more recent years Penny Gay has followed calling her the "queen of Highbury society" and Pam Morris likens her to "all princesses" $(58,88) .{ }^{13}$ The monarchical language registers not only Emma's superiority and condescension, but also the inherent power and loneliness of her situation. Highbury "to which Hartfield, in spite of its separate lawn, and shrubberies, and name, did really belong, afforded her [Emma] no equals" (9). This dichotomy of simultaneous separation and belonging reflects that while she has significant agency, Emma is still bound to Hartfield and the care of her father, which cannot help but isolate her. Lorna Ellis claims that her "status as an unmarried daughter of an invalid father aids her in her self construction by giving her an excuse for remaining apart from the rest of the community," but it is also a separation that is partially forced upon her rather than chosen (121).

Mr Woodhouse and Emma's relationship places numerous demands and restrictions on her. Nowhere is this so poignantly depicted as when she consciously sets aside her own feelings to cater to his, such as when she must cover her "first" grief at the loss of Miss Taylor after her wedding to smile and chat "as cheerfully as she could" to keep him from bleak thoughts (8-9). Their relationship is a complex one and while the negative ramifications of Mr Woodhouse's dependence and indulgence of Emma are often emphasised, I argue that this must be tempered with the acknowledgment that his unconditional love is also crucial in creating her defining confidence and sense of self. Emma is placed in the difficult position of negotiating the dual roles of mistress and daughter of the house, and the contradictory positions of power each entails. She must at once provide for and defer to her father who still presides at Hartfield without remaining isolated from her wider community.

Unlike other Austen heroines such as Elizabeth Bennet and Anne Elliot, or even Jane and Harriet within her own novel, Emma must develop without a change in locale to prompt such a transition. Thus, in both Mr Woodhouse's continued presence and her limited mobility, Emma's trajectory breaks from the traditional

\footnotetext{
${ }^{13}$ Margaret Berendsen also calls her "Queen Emma" (97).
} 
Bildungsroman model. More particularly, Claudia Johnson observes that Austen typically removes "her heroines from the parental abode altogether precisely in order to free them from" filial obedience and "to oblige them to think and act for themselves" (84). Elizabeth's trips to Kent and Derbyshire, or Anne's to Lyme and Bath come to mind. Emma's persistent presence at Hartfield is consequently a decisive break from Austen's previous narrative pattern and as such underscores the importance of Emma remaining exactly where she is. On a logistical level Emma is rooted at Hartfield by necessity, as her father is fixed there and cannot abide change. Moreover, her very identity is predicated on her unmarried status and physical location in being 'Miss Woodhouse of Hartfield.' Unlike the mobile and liminal other women in the novel, Emma barely travels and has been brought up engrained with the sense of security and implicit knowledge that she belongs at Hartfield.

Hartfield appears to hinder Emma's development in its implicit opposition to change; however, it hones her ability to introduce transformation. Pam Morris claims, "Hartfield, then, as a place, symbolises a regime of vertically regulated order, and absolute, unchanging values" (89). As the home of a master who lives "hating change of every kind," Hartfield is a space of regulation and fixity, which Emma must maintain to accommodate her father, but also alter to ensure she does not stagnate (9). While Hartfield can be oppressive, Austen stresses the importance of Emma's adroit ability to implement change in any form. For instance, we are told of "the large modern circular table ... which none but Emma could have had power to place there and persuade her father to use, instead of the small-sized Pembroke, on which two of his daily meals had, for forty years been crowded" (325). Emma's replacement of her father's old and trusted table, for a new more practical one, is a resounding achievement given Mr Woodhouse's horror of any alteration. Austen famously likened her work to miniature painting, and this small detail of the table serves as a quiet check on scholars who are too absolute on the unchanging status of Hartfield. ${ }^{14}$ On a larger scale, Emma boasts of her ability in matchmaking Miss Taylor and $\mathrm{Mr}$ Weston's relationship. She claims, "If I had not promoted Mr. Weston's visits here, and given many little encouragements, and smoothed many little matters, it might not have come to anything after all. I think you must know Hartfield enough to

\footnotetext{
${ }^{14}$ Austen famously likened her writing to the "little bit (two Inches wide) of Ivory on which I work with so fine a Brush" (Letters 337). Rachel Brownstein notes of Emma that "part of the point is how much little things matter" (Why Jane Austen 197).
} 
comprehend that" (14). Emma here presents Hartfield as a metonym for $\mathrm{Mr}$ Woodhouse himself, and we see how her amalgamation of house and master at once removes any implicit critique on Mr Woodhouse, while still clearly acknowledging the reality of the situation - namely, the difficulty of introducing change in any form at Hartfield, let alone something as significant as the removal of one of its most crucial members. In the introduction of the new dinner table and the departure of Miss Taylor, Austen foreshadows the much more significant and drastic change Emma will later implement at Hartfield in her marriage to Knightley and emphasises the necessity of Hartfield's evolution.

While Emma may be able to alter aspects of her surroundings, it is apparent that she requires a momentous change to ensure her continued growth at Hartfield. While her early disavowal of marriage is a refreshing rally for female autonomy and independence based on the freedoms and privileges of her position, it does not acknowledge the restrictions living solely with her father places on her personal growth. Whereas Miss Taylor, Jane, and Harriet's unmarried state is defined by a precarious indeterminacy, Emma's is characterised conversely, but no less problematically, by an excess of security and certainty - a state which cannot remain the same in the face of the narrative's drive for transformation and fulfilment. The full weight of Emma's situation only impresses itself upon her when she belatedly realises her true feelings for Knightley. ${ }^{15}$ Upon his removal to London, Emma imagines the winters of her life stretching out before her in monotonous continuity (396). The "prospect before her now, was threatening to a degree that could not be entirely dispelled - that might not be even partially brightened" (395). Whereas Jane was oppressed by the knowledge that her current state would soon come to an end, Emma is faced with the possibility hers might never do so. Austen unites Jane and Emma in these moments of imagining a bleak future stretching before them which they feel powerless to alter. While Austen does not dwell on this sense of female

\footnotetext{
15 There is a persistent critical tradition of describing Mr Knightley as a father figure for Emma. Margaret Berendsen calls him "a substitute father" (104), Sue Birtwistle opts for the more placatory, "a bit of a father-figure" (80), and Kit Kincade sees Emma as having "two fathers to contend with" (55). My argument reads $\mathrm{Mr}$ Knightley more as a compatible romantic partner for Emma who operates with her on a basis of equality. Emma has not been moulded by Knightley's influence, unlike Edmund Bertram with Fanny in Mansfield Park — who "Having formed her mind and gained her affections ... had a good chance of her thinking like him" (91).
} 
helplessness, in these moments she quietly confronts the vulnerability and melancholy indeterminacy often experienced by young woman on the brink of an uncertain future.

Emma's internal division between her feelings for Knightley and her loyalty to her father calls forth the dichotomous desire for her circumstances to remain the same and yet be completely altered. This is precisely the fraught moment of compromise or 'shedding' feminist Bildungsroman scholars' argue typifies the genre and renders it permeated by female disillusionment and disappointment. Emma yearns for the love, change and companionship, which would be gained by fulfilling the marriage plot in marrying Knightley; however, doing so would seem to necessitate abandoning her father, place and position at Hartfield - all crucial aspects of her identity. She refuses to make the narrative and societally sanctioned linear transition to become a 'wife' at the cost of her role as a 'daughter.' Whereas Harriet and Jane are ready to be established elsewhere, Emma's love and responsibility to her father renders such a thought unthinkable. She never considers the possibility of removal to Donwell or anywhere else and the thought of leaving her father fills her with dread. What she wishes for is not a change in circumstance, but simply no deviation from what was: "Could she be secure of that, indeed, of his never marrying at all, she believed she should be perfectly satisfied.-Let him but continue the same Mr. Knightley to her and her father" (390). Emma essentially desires not to become Mrs Knightley but for Knightley to remain as he was - an honourary Woodhouse.

\section{The Necessity of Mr Woodhouse at the Novel's Close}

Emma solves the heroine's dilemma by famously closing not with the relocation of the newly wedded hero and heroine to Donwell Abbey but Knightley's absorption into the Hartfield familial unit. This unorthodox move has prompted responses of surprise and weariness as to its ramifications for Emma's development and her relationship with Knightley. There "is always an element of violence in the process of closure" which in the nineteenth-century novel is predominantly brought about through "death and marriage" (Monk 349). However, Emma's ending is notable for the absence of this necessary violence to close the novel. While marriage is clearly present in the three weddings that comprise the narrative's end, the only funeral is Mrs Churchill's. We cannot help but ask why are Mrs Weston's turkeys sacrificed to enable Emma and Knightley's union, instead of Mr Woodhouse himself? (452). 
If the ending is read with an overt emphasis on the novel as a marriage plot then $\mathrm{Mr}$ Woodhouse is more easily relegated to being, in the words of Nancy Armstrong, a "selfish monster" ("Gothic" 241). His dependence on Emma and abhorrence of marriage are certainly established from the first chapter as obstacles that must be overcome. As Richard Jenkyns rather whimsically puts it, $\mathrm{Mr}$ Woodhouse is "the 'bad fairy' who has to be defeated if the heroine is to be happy" (157). While this glances over the devastating effect Mr Woodhouse's death would have on Emma, there is no arguing with the sentiment that his presence seems to effectively block any chance of her marriage. As Mrs Weston acknowledges, the "difficulty of disposing of poor Mr. Woodhouse had been always felt" in any of her thoughts of Emma marrying and Austen poses this question to the reader focused on the marriage plot (437). Leland Monk explains that the "murderous qualities" of 'closure are registered in the way we say a novelist 'kills off' a character at a convenient time and for finely plotted reasons" (349-350). This form of convenient 'killing off' is exemplified by Mrs Churchill's death, which allows Frank and Jane Fairfax to marry just when it seems a gulf is about to divide them. The novel's validation of this marriage plot device makes its absence in the case of $\mathrm{Mr}$ Woodhouse even more prominent and defiant.

Mr Woodhouse appears to be protected from death for the duration of the novel and his immovable position also extends to excluding the possibility of relocation. His valetudinary habits and intense aversion to change removes any chance he could be persuaded to live at Donwell. As Knightley acknowledges, "such a transplantation would be a risk" of Mr Woodhouse's "comfort, perhaps even of his life, which must not be hazarded" (E419). While Mr Woodhouse proclaims that young "ladies are delicate plants", it is ironically his own constitution that would not survive the necessary transplantation to a new home that a bride undergoes (273). This connection is made explicit by the only other use of 'transplant' in the novel, which is by Mrs Elton- "Whenever you are transplanted, like me, Miss Woodhouse, you will understand how very delightful it is to meet with any thing at all like what one has left behind" (254). The irony is that Emma, as well as her father, will be spared such a transition.

In a different kind of narrative, if Mr Woodhouse were simply a monstrous 'bad fairy', Emma could simply run away and escape his influence with the reader's full approbation. However, Mr Woodhouse is no such simple caricature and the love 
he and Emma share renders such a move incomprehensible. One of Emma's most sympathetic and unselfish moments is her intense recoiling at the thought of abandoning her father. A "very short parley with her own heart produced the most solemn resolution of never quitting her father. - She even wept over the idea of it, as a sin of thought. While he lived, it must be only an engagement" (407). Consequently, Mr Woodhouse's presence is just as permanent at the novel's end as it was at the start, where he solidified his significance through speaking the first direct dialogue of the text.

Knightley and Emma making Hartfield their marital home can be viewed as the most intense expression of Mr Woodhouse's power in the novel and is a frequent source of critical disagreement. The answer to why Mr Woodhouse's presence is necessary to the final dynamic of Emma hinges on whether the ending is perceived as a change or not. Austen speaks to this dichotomy when the newly engaged Emma and Knightley return to Mr Woodhouse and sit "down to tea-the same party round the same table - how often it had been collected! - and how often had her eyes fallen on the same shrubs on in the lawn, and observed the same beautiful effect of the western sun!-But never in such a state of spirits, never in any thing like it" (406). The repetition of the 'sameness' of the configuration and setting is emphasised and contrasted with the intense alteration in Emma's emotions and the progression of her self-awareness. Everything is the same and yet completely different. ${ }^{16}$ For Linda Bree, the ending's "conscious reprise" of the beginning of the novel speaks for "continuity rather than change" and Emma's return to Hartfield after her seaside honeymoon is a "return" to "claustrophobia" (140-141).

The possible sense of constriction in the novel's ending unsettles critics who see Emma's remaining at Hartfield with her father as likely to stunt her growth. Colin Jager views Emma as perhaps facing "a marriage that condemns her to adolescence" (96). ${ }^{17}$ Similarly, Gregg Hecimovich views Knightley and Emma's future as "living in a kind of suspended animation" caring for Mr. Woodhouse (65). For Jager and Jenkyns, Mr Woodhouse's continued presence at the novel's close is disturbing and

\footnotetext{
${ }^{16}$ Emily Auerbach expresses this as she notes that while the "same inert configuration of Emma, Mr. Knightley, and Mr. Woodhouse" at the end of the novel seems "static" it emphasises the change the hero and heroine have undergone (230).

${ }^{17}$ Jenkyns postulates that "Emma must still live with the man who has shackled her" (165) and Hecimovich sees Knightley's relocation to Hartfield as one of the "biggest blunders in the comic novel tradition" (53).
} 
damaging. They concur with Mrs Elton, surely a dubious honour, that it is a "Shocking plan, living together" and will "never do" (439). However, others view the ending as a radical approach to marriage and an indication of Emma and Knightley's integration into the community. Emily Auerbach praises Knightley's move to Hartfield as indicative of the "notion of an open, equal, and fair marriage" between the protagonists that "radically redefines" the institution (230). ${ }^{18}$

None of these critical responses consider if the ending could be a statement on the beneficial necessity of Mr Woodhouse's presence in and of itself. Just as Emma requires Knightley to challenge and understand her, she also needs Mr Woodhouse to bring out her best traits. While the marriage plot places sole emphasis on the wedded couple at the novel's close, with perhaps a token glance at other characters, $\mathrm{Mr}$ Woodhouse's presence emphasises his importance and underlines the manner in which Emma retains her identity and functions as part of a wider community, not simply as part of a couple. His presence also shows a commitment to the past and the need to support the more vulnerable members of society. For A. C. Bradley, Mr Woodhouse, like Miss Bates, is both "the object equally of our laughter and our unqualified respect and affection" (237). While they have their eccentric foibles, they are both crucial social operators in their constant creation of the various social engagements and formations that shape Highbury life. Mr Woodhouse is never demeaned or mocked by a character and Austen continues this "respect and affection" by not simply killing him off like a narrative device that has fulfilled its purpose like Mrs Churchill. Austen refuses the traditional narrative closure and instead uses $\mathrm{Mr}$ Woodhouse to make a statement on Emma, and all of Highbury's, continuing commitment to him and the more traditional values he embodies.

Far from being an irrelevant or tokenistic presence, $\mathrm{Mr}$ Woodhouse is presented by Austen throughout the novel as integral to the functioning of Emma and Knightley's relationship (81). While the couple often bicker, tease and disagree, all vital aspects of their relationship, their moments of unity where they act with mutual understanding are always centred on Mr Woodhouse. He is the catalyst that prompts them to act intuitively and effectively "together as a team" (McMaster, Emma 129). A series of integral moments occur between Emma and Knightley, which are

\footnotetext{
${ }^{18}$ Similarly, Joel Weinsheimer exclaims that "Emma's refusal to leave Mr. Woodhouse deserves the highest praise, for it epitomizes the novel's central truth, that only within community is self-realization possible" (94).
} 
triangulated through Mr Woodhouse and implicitly show the couple's compatibility and the necessity of Emma's transition into both a daughter and a wife.

The most striking example of Emma and Knightley's suitability is demonstrated in their efforts to calm and extricate Mr Woodhouse from the Christmas Eve party at Randalls, as mentioned at the start of this thesis. While the other characters' efforts prove futile in helping Emma ease her father's panic, Knightley leaves unnoticed, checks the road, consults the coachmen and returns with assurance they will all be able to return to Hartfield safely (121). The exchange at Randalls shows "obliquely the effective moral and social basis" of Emma and Knightley's relationship (Sturrock 96). The combination of her attentiveness and his quick thinking soon deescalate the situation. The conversation that follows between them is distinctive for its succinct simplicity in a novel so preoccupied with witty word play and verbosity:

'Your father will not be easy; why do you not go?'

'I am ready, if the others are.'

'Shall I ring the bell?'

'Yes, do.'

And the bell was rung, and the carriages spoken for. (122)

This exchange highlights the inherent understanding between Emma and Knightley in these moments of crisis surrounding her father and illustrates that they are "essentially compatible partners" (McMaster, Emma 129). They speak to each other in the same register almost rendering words unnecessary. Emma and Knightley similarly placate Mr Woodhouse and ease a tense situation during a dinner with John and Isabella, despite having recently disagreed about Harriet and Robert Martin. Both scenes reveal that $\mathrm{Mr}$ Woodhouse is the conduit through which Emma and Knightley function most effectively. Knightley's speech in both moments of crises is so straightforward and subtle that Emma, and perhaps some readers, are unable to see the way in which they also function as an expression of romantic interest and compatibility. With Frank prondcing rhetorical flourishes such as, "You order me, whether you speak or not. And you can be always with me. You are always with me", Knightley's "Shall I ring the bell" initially falls rather flat $(346,122)$. However, part of Emma's education is realising the true value of what she already has. Emma's relationship with Knightley is thus an amalgamation of her past and future - through her father's presence and the fact that her husband is the man who has been standing beside her all along. 
While other characters serve to emphasise Emma and Knightley's differing perspectives, changing opinions and personal growth, Mr Woodhouse remains their point of complete agreement and continued unity. Later in the novel after Knightley's proposal Emma thinks, "Such a companion for herself in the periods of anxiety and cheerlessness before her! - Such a partner in all those duties and cares to which time must be giving increase of melancholy" (420). Her allusion to the inevitable decline of Mr Woodhouse highlights how even more necessary Knightley's presence will be for both father and daughter. Over the course of the text Knightley and Emma bicker and disagree over characters as diverse as Mr Elton, Harriet, Robert Martin, Jane Fairfax, Frank, and Miss Bates. Their ability to argue and vocalise their difference in opinion is a fundamental aspect of their relationship; however, it is vital to note that they never disagree on Mr Woodhouse. Knightley and Emma "are represented as both fighting together and working together. Their dialogues show the two lovers acting together within a community, and, in part, for the sake of that community" (Sturrock 96).

Patricia Meyer Spacks claims "eighteenth century novels, especially novels about women, explained their youthful virtue as largely the consequence of adult guidance" (164). However, Emma inverts this principle as the heroine develops her empathy and compassion through caring for and guiding her father. Emma and Knightley learn to be deeply attuned to each other and Mr Woodhouse's thoughts, feelings, and needs in order to provide for his comfort in any situation. Indeed, these skills could be said to put them in strong stead for any small feet that may patter along Hartfield's halls. Consequently, Mr Woodhouse's presence at the novel's close can be seen as not simply as a plot device to blindside the reader or an aesthetic choice to complicate the "picture of perfection", but a necessary component and definitive statement of Emma and Knightley's intrinsic suitability and continued unity (Letters 350). As Mrs Weston says of the arrangement, it "was all right, all open, all equal" (Emma 437).

\section{The Consequences of the Ending Emma's Hybrid State of Wife and Daughter}

In Emma and Knightley's marriage and his consequent relocation to Hartfield, Emma is spared the severing of her past and future self, creating instead an amalgamation of the two. Austen presents this hybrid state through her patterning throughout the novel 
of Emma and Knightley's most compatible moments and symbiotic interactions being centred on Mr Woodhouse. These interactions consequently provide us with the embryonic reflection of what their married life will look like. Emma's role as a daughter has always been implicitly entwined with her romance with Mr Knightley and their marriage is consequently a continuance of this dynamic, while also providing the opportunity for her further growth.

Emma does not need to abandon her role of daughter to become wife but can instead simultaneously perform both. Colin Jager cynically sees Emma sighing at the beginning of the novel "not for Miss Taylor but for herself, and in the face of a narrative that will, by its end, have prepared her so thoroughly for marriage that she can say, with all apparent honesty, that far from wishing for impossible things she now "wishes for nothing"' (77). For Jager, Emma is beaten both by the patriarchal system and the narrative form of the marriage plot, leaving her with an empty conventional ending of marriage. Conversely, I propose that Emma transcends such a hollow conclusion. She will continue caring for her father and retaining all the importance of her position as mistress of Hartfield, while also becoming the mistress of Donwell Abbey. While this is not to say that the arrangement will not have its own difficulties, what is striking is that instead of having to abandon her past self, Emma is able to integrate her new identity with her old.

Emma's ending subverts the Bildungsroman 'classification principle' while also highlighting the heroine's own acceptance of less strictly codified social strata. The classification principle renders "narrative transformations" as "having meaning in so far as they lead to a particularly marked ending" (Moretti 7). Emma's close allows the heroine to remain predominantly classified by her own character, rather than the role of 'wife' or 'daughter.' Emma was once similar to her father in her "predilection for the socially-privileged and the strongly classified" (Murray 969). However, by the end of the novel she has progressed to a more mature self-awareness and has developed a system of classification more fundamentally based on ideas of meritocracy rather than class or status. This is epitomized in her acknowledgment that Robert Martin, whom she previously saw only as a lowly farmer, possesses "all the appearance of sense and worth" (451). The novel's emphasis on valuing a character's moral worth over their social position and connections reflects the shift towards meritocracy that will be more vividly depicted by Austen in her later novel Persuasion. Emma's evolving opinions reflect her eventual registering and acceptance 
of the broader dynamics of change becoming felt in Highbury, as a new social order is beginning to emerge.

Marriage in Emma takes on a less familiar guise, reflecting the necessity of people and institutions morphing and adapting to reflect the changing and increasingly unstable times. Knightley's highly unusual relocation to Hartfield underscores the equality of their union and reverses the typical heroine's integration into the husband's household and family. Both Jane and Harriet are enveloped into a new family on the event of their marriage-Jane and Frank will live at Enscombe with Mr Churchill, and Harriet will reside with Mr Martin, his mother and sister. While Knightley living with Emma and her father is in some ways an extension of this melding of new families and reshaping of a community, it also underscores the equality between him and Emma in his undertaking of a transition that is traditionally undertaken by the young bride. In "moving to Hartfield, Knightley is sharing her home, and in placing himself within her domain, Knightley gives his blessing to her rule" (Johnson 143). Austen makes a pronounced effort to reinforce the equality of Emma and Knightley's marriage. Even at the formation of their union, during the span of his proposal Knightley passes from desolation to euphoria, and Emma's “change was equal" (404-405). ${ }^{19}$

Emma's ending provides closure on the basic level of the marriage plot, but it also creates a sense of prospects opening up to Emma. Emma and Knightley's union certainly represents marriage as the "origin of change" and consequently transforms the previously static space of Hartfield. Whereas the vocabulary of finality permeates the marriages of Miss Taylor, Jane, and Harriet with everything "secure" and "settled" for the women, no such language is used to describe Emma and Knightley's union. On the level of the marriage plot, Emma's future is indeed settled, but in the unconventionality of the ending Austen pushing against the sense of finality inherent in a wedding closing a novel. Austen "ends Emma" with "a marriage that is a perpetual conversation" (Tandon 161). Austen refuses to simply sever Mr Woodhouse for the sake of narrative closure and this refusal allows Emma to continue defining her marriage and future identity on her own terms.

\footnotetext{
${ }^{19} \mathrm{Mr}$ Knightley also wishes that Mr Woodhouse "would be half as easily convinced as John will be, of our having every right that equal worth can give, to be happy together" (434)
} 
Earlier in the novel, the narrator gives the history of Mr Weston's first wife who had the strength of character to marry a man her family disapproved of but could not help but miss the luxuries of the life she left behind. She was trapped between her conflicting past and present, as although she "did not cease to love her husband" she "wanted at once to be the wife of Captain Weston, and Miss Churchill of Enscombe" (17). However, the inability of these identities to coexist and left her disillusioned and displaced. Emma is poised as a direct counterpoint to Mrs Weston née Churchill. Instead of suffering the same fate, she instead facilitates a hybrid state of wife and daughter that maintains her past identity while also allowing a future one to develop. In many ways this also looks forward to Persuasion, where the conclusion of Anne becoming a naval wife further registers the need for a more controversial or unusual marriage and narrative ending to appropriately register both the complexity of the female experience and the increasingly turbulent social and political milieu of the time.

To some, Emma's end may seem a disappointing anticlimax that reduces yet another a brilliant and defiant heroine into simply another wife. And yet, in her very marriage to Knightley and continuance with her father at Hartfield, Emma is no ordinary Highbury matron, or indeed female protagonist. In this instance, the daughter who stays and 'tends the home fire', still experiences meaningful change and progression. She also, unlike countless other nineteenth-century novels of female development, does not have to enact any form of compromise or die as a sacrifice to her hostile social environment. Moreover, the triumphant unconventionality of the novel's end in the continued presence of Mr Woodhouse defies the finality and sense of loss inherent in a traditional female Bildungsroman. Emma's development parallels that of Highbury, as Austen optimistically depicts a society adapting to change through marriages that cross class divides or incorporate the older generation in their formation. Austen emphasises that both Emma and Highbury will be flourishing, not regressing, in their new states. As Emma herself declares, "Oh! I always deserve the best treatment, because I never put up with any other" (443). 
Maggie Tulliver and the Backwards Flowing Tide

Female Belonging and the Necessity of Return in The Mill on the Floss

"We follow back to the heart the retreating blood that had left the cheek pale; we know every gleam of hope and pang of despair that runs through mind and soul, as the familiar landmarks are passed, and she is drifted down with the flood." - Spectator Review of The Mill on the Floss (7 April 1860)

"Oh, it is difficult,- - life is very difficult! It seems right to me sometimes that we should follow our strongest feeling; but then, such feelings continually come across the ties that all our former life has made for us, - the ties that have made others dependent on us - and would cut them in two." - The Mill on the Floss (454)

George Eliot explores in The Mill on the Floss the same dilemma Austen does in Emma - what is to be done with a heroine who is inherently tied to both her father and her habitat? The negotiation of these ties of the past, while simultaneously attempting to create a new future, is inherently a fraught feminine experience. As Lawyer Wakem proposes, albeit from a position we are explicitly invited to criticise, "We don't ask what a woman does—we ask whom she belongs to" (432). Just as Emma is grounded at Hartfield with Mr Woodhouse, so too is Maggie defined by her family home of Dorlcote Mill and moulded by her relationship with Mr Tulliver. However, where Emma's whims and desires govern her domestic sphere, Maggie's are constantly thwarted. Where Emma presides-Maggie is an outsider. This dynamic is enacted in one of the most memorable moments of the novel when the young protagonist decides to chop her hair in a moment of defiant rage. In the aftermath of this transgression Maggie sneaks back downstairs and standing in the liminal space of the parlour doorway sees custards on the side table and her brother and cousin "with an empty chair between them" (108). The temptation to enter overpowers her, but "she had no sooner sat down than she repented, and wished herself back again," as her wild and altered appearance causes a flurry of horror and condemnation from the assembled family (108). This episode presents the central dilemma of the novelMaggie is inherently bound to her home and yearns to belong but is simultaneously incapable of peacefully existing there. Maggie has a chair at the table but her attempt to fill it causes only disturbance and disruption. 
Maggie's life is comprised of violent attempts to reconcile her passionate inner life with the outward world of duty which she must operate in. This dichotomy of partial belonging leads to an internal division in Maggie as her desire to honour bonds of familial duty wars with her hunger for a different reality to the mundane existence before her. Maggie's wishing herself 'back' to the safety of the attic epitomizes the way in which her internal division is repeatedly expressed throughout the novel. Whereas so much of The Mill on the Floss impresses upon us the inevitable forward flow of time and progress, Maggie's movement, both mental and physical, is instead defined by a sense of return. Nowhere is this sense of reversed momentum more apparent than at Maggie's defining moment of crisis, as she glides too far on the river with Stephen towards scandal and social alienation, and her progress is "helped by the backward-flowing tide" (467). While Maggie strains towards new horizons she is inevitably brought back to where she began. In this she is symbolically bound to the mill at the centre of the novel, which constantly moves, but can never progress forward. Maggie's pattern of return has not gone unnoticed in scholarly discussion. David Smith suggests The Mill on the Floss's "largest structural pattern" is "one of venture and return" (161). Similarly, Margaret Homans proclaims that the novel's "plot patterns turn on Maggie's continual need ... to reaffirm her ties with home" (129). However, these observations, while astute, are subsidiary to their other claims and there is a need for closer examination of this crucial pattern of return. In this chapter I seek to explore what this pattern fundamentally means to our reading of Maggie's experience and particularly the novel's divisive end. Similarly, whereas critics often focus solely on Maggie's intense relationship with Tom, this chapter presents her bond with her father as being just as significant and influential for her development.

Austen and Eliot are both concerned with the young female's ability to develop and gain new vistas of experience while also honouring familial bonds. Austen achieves this in Emma through depicting a hybrid state of daughter and wife that allows Emma to determine the parameters of her future. However, for Eliot in The Mill on the Floss, marriage is no longer the inherent and satisfying answer that it was for Austen 45 years earlier. In the previous chapter I suggested that while we leave Emma in the same geographical location we found her in, she is faced with an opening out of prospects stretching ahead of her. And although Maggie also ends where she began, her movement is conversely one of backwards momentum, and she 
ends the novel dead, not married. This chapter argues that Maggie's death, as the culmination of a series of returns back to the Mill, is the only fitting conclusion for her. In death, she inhabits the same physical location as where she was born and consequently enacts the circular spatial logic of the novel. In this chapter I first examine the patterns of escape Maggie establishes in her childhood to avoid the strictures of domestic life. The second section moves to establish three narratives which Eliot proposes for Maggie's future-renunciation, vocation, and marriageand illustrate how each are disregarded in turn for the final controversial end of the novel.

The sense of Maggie's turbulent progress mirrors her society's, as Eliot sets the novel at a moment of fraught historical transition. The Mill on the Floss was "written in 1859-60 and set in 1829-44 (precisely between the two greatest economic crises of the Victorian age: the Companies Mania of 1825-6 and the Great Railway Mania of 1844-7)" (Kreisel 116). The tension of this moment is most clearly depicted in the figure of Mr Tulliver, who is unable to adapt to the new mercantile and social order he finds encroaching on his daily life. While Maggie is more adaptable and mobile than her father, she is similarly unable to progress beyond the mill and create a life elsewhere. Moretti notes that modernity "seeks its meaning in the future rather than in the past," but for Maggie it is the past that imbues her with meaning and a sense of belonging (7).

\section{Maggie's Childhood}

\section{The Original State and the Reality of the Daisied Fields}

The experience of childhood is at the heart of The Mill on the Floss and critics often note the idealised quality of Eliot's depiction of it. Perhaps the most intense instance of this is the narrator's nostalgia at the novel's dramatic close. At the moment of death, Maggie and Tom are returned to the days of their childhood where they "roamed the daisied fields together" (517). Sally Shuttleworth posits that "Maggie's childhood takes on, in retrospect, the qualities of an Edenic, atemporal realm" (65). And, Joshua Esty similarly calls the novel a "postlapsarian epigram" and notes that "after the fall, grown women, like modernised societies, can only tell and retell their histories in an impossible attempt to reinhabit imaginary innocent sites like premodern St. Ogg's or the girlhood of Maggie Tulliver" (149). What both Shuttleworth and Esty's comments register, through their use of "retrospect", "retell", 
and "reinhabit", is that the nostalgia for an idealised childhood is a narrative the novel later tells itself. ${ }^{20}$ While Eliot dwells intensely on Maggie and Tom's formative years, scenes of literal or symbolic daisy picking are few and far between. What really characterises these years, especially for Maggie, is the intensely difficult manner in which she must navigate the trials, tribulations and condemnations of being a young girl 'out of the swim.' She is constantly attempting to violently assert herself against a feminine ideal that repeatedly finds her lacking ${ }^{21}$. This section seeks to establish not the daisied fields, but the actual parameters of Maggie's childhood that construct, both structurally and symbolically, her movement throughout the rest of the novel.

Maggie is a whirlpool of vitality and destruction in the otherwise sleepy world of St Ogg's. Her "recurrent pattern of action is to enter worlds and explode them" (N. Auerbach 157). However, her tragedy lies in the fact that, so far from wanting to demolish and destroy, what she really desires is to be praised and accepted. Maggie has a "blind, unconscious yearning for something that would link together the wonderful impressions of this mysterious life, and give her a sense of home in it" (262). Her fleeting moments of acceptance and unity in her childhood come from three, often entwined, sources - the Floss and connected mill, her father, and her own imaginings. These allow Maggie to create her own worlds where she finds temporary peace in the eye of the storm. However, in doing so, she is distanced both from her reality and the community that surrounds her.

As both child and adult, Maggie is defined by violent and unrestrained movement. This connection is implicit from the novel's start as the young protagonist gazes at the rushing water and unresting wheel of the mill, to its end where she transitions from observing to being fully immersed in the tumultuous flooded Floss. In keeping with this, Maggie's childhood rebellions are presented as a series of forceful and transgressive motions: beating and grinding her wooden doll (72), aggressively cutting her hair (104-109), pushing the placid Lucy into the mud (137-141), and

\footnotetext{
${ }^{20}$ Critics often miss this nuance and simply claim that Eliot idealises childhood. For instance, Eithne Henson notes that Eliot's landscapes are pastoral both in terms of being pre-industrialisation farming landscape and "also the idyllic stasis of a sentimentalised childhood memory" (206).

${ }^{21}$ The difficulty of Maggie's childhood must be registered for what it is, rather than disregarded as idealisation, for the narrator's call to empathy for those early childhood grievances to maintain its full force: "Surely if we could recall that early bitterness, and the dim guesses, the strangely perspectiveless conception of life that gave the bitterness its intensity, we should not pooh-pooh the griefs of our children" (107).
} 
running away to join the gypsies (143-153). Maggie's moments of freedom and transgression predominantly occur outside and she must then be recaptured and returned back into the familial unit, and implicitly, the domestic sphere.

Our first introduction to Maggie in the novel's prelude is as an unnamed little girl standing at the water's edge entranced by the movement of the mill's "unresting wheel” before her (52). In the dreamy and dozy pastoral setting, Maggie is entirely focused on the source of kinetic energy, power, and transformation - the very forces in herself that society seems to condemn and deny, while harnessing them instead in natural resources and her male counterparts. Whereas the mill seems to dominate the scene and assert its permanence, the landscape reflects the ephemeral nature of the moment, and we later learn that the mill itself is not even the original structure but was rebuilt after an earlier flood (287). The sun's rays are "transient" in the "leafless time of departing February" (51). This seasonal emphasis reinforces the inevitable cycle of time - it will soon be March, the sun's rays will eventually stay longer, the trees will gain new leaves, and the little girl will become a woman. However, the novel's controversial ending cuts off this implied natural progression, as instead of moving forward, Maggie will return and be 'cut down' on the brink of womanhood, just as the mill will be destroyed along with her in the flood. The "image of Maggie permanently suspended at the threshold of committed and constrained womanhood cannot last" but "is, nevertheless, the lyric possibility at the heart" of the novel (Esty 116).

The transience of this opening tableau is also implicit in the narrator's decisive proclamation that it "is time the little playfellow went in" (52). Our first glimpse of Maggie, not in a domestic setting but instead immersed in the landscape, connects her with unrestrained nature and hints that perhaps she is, as her mother believes, "a wild thing" (57). ${ }^{22}$ The difficulty of Maggie's excursions lies in her "wandering” beyond the place of home: "it is wandering, and the threat to social order that this uncontained mobility represents, which constitutes the true wildness of Maggie's behaviour" (Mathieson 91). Maggie's innocent childhood wanderings foreshadow her later more secretive and socially damaging excursions with Philip Waken and Stephen Guest.

\footnotetext{
${ }^{22}$ Maggie's wildness, and connection to the landscape and relationships of her childhood, echo Catherine Earnshaw and her similarly fraught experience of selfdivision and societal expectations in Wuthering Heights - "I wish I were a girl again, half savage and hardy, and free" (125).
} 
Each of these is followed by a fraught attempt at integration back into the familial unit, but for now, the young Maggie's return is comparatively straightforward, although not painless. She cannot stay out in her daydream reverie and the dwindling sunlight by the Floss but must return to the safety and stability of the house. However, the house is predominantly a source of conflict rather than comfort for Maggie. When she returns inside, she is accosted by her mother's attempts to force her to conform to a more traditional mode of femininity, in this instance by trying to persuade her to make a counterpane for her Aunt Glegg (58). Maggie's refusal leads to her mother's disappointed remonstrance, a response that is repeated throughout Maggie's childhood and defines her inability to conform to the Dodson feminine and familial ideal.

As there seems to be no place for Maggie to operate as herself in the daily life of the household, she seeks out sanctuaries unmarked by domestic strictures where she can carve out her own worlds. While Maggie's first instinct is to escape outside, the attic is her "favourite retreat on a wet day" (71). Although this is an internal space, it is separate to the daily functioning of the house. Maggie retreats to the attic to escape her mother's anger after she defies her — such as when she dunks her head in a basin of water to prevent it from being curled (7). In this cavernous space Maggie "fretted out all her ill humours" and "soothed herself by alternatively grinding and beating" the head of a wooden doll against the brick wall (71-72). In this violent and repetitive exertion of force, Maggie echoes the mill that provides her family's livelihood, and expels her turbulent and pent up emotions. Just as gazing at the mill at the novel's start completely enraptures Maggie, while she beats the fetish she sobs "with a passion that expelled every other form of consciousness" (72). Maggie is not only able to expend her tumultuous emotions here but she also loses any consciousness of both selfhood and the external world in this repeated, aggressive motion. While her attempt to fill her empty chair caused consternation and conflict, the attic is bound to no social strictures or codes, and instead Maggie can take "wretched pleasure" in her sobs, creating a "hollow resonance that came through the long empty space of the attic" (80). Here she can take up space and voice her emotions without condemnation. ${ }^{23}$ The attic not only allows violent release but is also

\footnotetext{
${ }^{23}$ Maggie's affinity with the attic echoes a letter Eliot wrote a few months before her father's death: "Oh the bliss of having a very high attic in a romantic Continental town, such as Geneva - far away from morning callers, dinners, and decencies"
} 
a space of transformation and imaginative freedom. In the encouraging emptiness and possibilities of the attic Maggie defiantly transfigures herself by cutting her hair (105). Mrs Tulliver speaks of how Maggie can often be found singing and talking to herself in the attic "forgetting all about meal times" just as she loses time roaming outside along the Floss (81). Both the attic and the Floss are places where temporal and societal concerns fade away and Maggie's thoughts and actions can operate unregulated.

To rebel from the narrow and restrictive domesticity forced upon her, Maggie retreats to other airy spaces where she can exert her own influence. The mill on the Floss is explicitly described as a separate sphere of existence where the "rush of water and the booming of the mill bring a dreamy deafness" that creates tranquillity and acts "like a great curtain of sound, shutting one out from the world beyond" (52). Maggie is drawn to this excess of noise and movement that paradoxically creates peace by drowning out everything else. Maggie and the mill are both defined by a sense of rapid motion and noise without apparent advancement. Again, not content to simply observe, she becomes part of the mill and loves "to linger in [its] great spaces" (72). This extensive space is implicitly contrasted to the ordered and confined nature of her mother's and aunt's parlours, and symbolically the domestic, feminine world that appears to await her. While Maggie is able to act unreservedly in these expansive spaces, the domestic areas require her to shunt herself into their outlines of female tractability and docility - a process of violent restriction and reduction.

Whereas cousin Lucy is praised for her ability to sit peaceably, Maggie is a whirlwind of destructive energy, as she accidentally leaves knocked over card houses and spilt glasses of wine in her wake. It is no wonder that she feels affinity to the "resolute din, the unresting motion of the great stones" which makes her "feel that mill was a little world apart from her outside every-day life" (72-73). This "little world' is one where energy is not only unrestricted but has been harnessed and celebrated for its force. Whereas the mill transforms the rushing water into a tangible utility, Maggie's voracious emotions, energy and imagination have no socially sanctioned outlet. As an adult, Maggie later yearns for a purpose, a function and

(Letters 184). This yearning for a claimed female space of creation and peace separate from domestic world foreshadows Virginia Woolf's cry for women to able to have 'a room of one's own'.

Note, for Eliot's letters I refer to George Eliot's Life, as Related in Her Letters and Journals, vol. 1., as edited by John Walter Cross. 
pathway to channel her own irrepressible energy and provide for those to whom the 'ties of life' have bound her. This desire is foreshadowed and physicalised by the way in which Maggie integrates herself into the mill. Her favourite part of the mill is the top story corn-hutch, where she can sit on the large heaps of grain and "slide down continually" (73). Through this cyclical motion Maggie once again mirrors the mill and finds joyful fulfilment. However, as she 'grows up' such a childish recourse is no longer an option for her, and Eliot must present us with alternate plots for her future. And yet, in her continued pattern of return, Maggie continues to reflect the mill's recurrent motion and her future is irrevocably bound up with the increasingly redundant structure.

Fittingly, the character who instinctively understands Maggie, her father, is also immutably bound to the mill. Mr Tulliver refuses to leave and adapt to a new location and life, even after his illness and disgrace. Just as the 'transplantation' of Mr Woodhouse from Hartfield cannot even be considered, so too does Mr Tulliver seem to be grafted onto the mill, and would not survive being severed from it: "he felt the strain of his clinging affection for the old home as part of his life, part of himself" (287). Mr Tulliver details the various transformations of the mill he remembers in his lifetime and explains to Luke, "I should go off my head in a new place. I should be like as if I'd lost my way" (289). ${ }^{24}$ His children have inherited this compulsion, as Tom and Maggie both return to the mill on the cusp of adulthood when their best chance of leading a fulfilling life seems to surely lie elsewhere. The ties of the past, but particularly the call of the mill and the remembrance of their father, exert a lasting control. Just as the mill is a space of freedom and belonging for the young Maggie to escape to, her father is the source that satiates her yearning for love, understanding, and acceptance.

The episodes of Maggie's childhood, and indeed life, are characterised by a pattern of transgression, flight, and return. While Mr Tulliver is alive this process is sanctified by his paternal authority and innate affection for his 'little wench.' His

\footnotetext{
${ }^{24} \mathrm{Mr}$ Tulliver and Maggie's sense of connection to the mill resonates with William James's study of sensation - "For the places thus first sensibly known are elements of the child's space world which remain with him all his life ... to the end of time certain places of the world remain defined for him as the places where those sensations were; and his only possible answer to the question where anything is will be to say 'there,' and to name some sensation or other like those first ones, which shall identify the spot" (35).
} 
indulgent laughter is commonly the means through which Maggie's disruptive behaviour is acknowledged and ratified. When Maggie refuses to make a counterpane for her aunt, cuts her hair and proves her knowledge of Latin, Mr Tulliver's response is one of approving laughter, in contrast to the often horrified, confused, or repulsed reactions from other family members $(58,105,181)$. Mr Tulliver finds Maggie's unconventional behaviour comical and a sign of his daughter's 'cuteness' and originality but his laughter also registers her status as an oddity or spectacle. ${ }^{25}$ Part of this paternal approval stems from their deep-rooted sympathy for each other. $\mathrm{Mr}$ Tulliver frequently shares his daughter's sentiments, such as her irritation and distaste for her overbearing Aunt Glegg, and consequently sees no need to reprimand what he himself sees as reasonable and justified. Early in the novel, when Mr Tulliver is conferring with Mr Riley, Maggie accidentally drops her book in her haste to assure her father Tom would not displace him (61). Mr Tulliver does not scold her about the book as "his heart was touched" and instead "laughed, with a certain tenderness in his hard-lined face, and patted his little girl on the back, and then held her hands and kept her between his knees" (61). In contrast to the open and emptiness of the attic and mill, this image of possession and encirclement expresses a different experience of comfort for Maggie through the inherent bond of belonging and affection between father and daughter. Whereas Mrs Tulliver and her sisters are so confounded by Maggie's 'otherness' they cannot own her as a true Dodson female, her father claims her as "his little girl," "his little wench" and takes "her part" $(61,153,80)$. However, in affirming both her sense of self and belonging to him, Mr Tulliver widens the gap between Maggie and her mother and extended family. ${ }^{26}$ The intense unity and understanding between father and daughter is vital in assuaging Maggie's turbulent

\footnotetext{
${ }^{25}$ While Mr Tulliver admires Maggie's 'cuteness,' he explicitly registers it as having a limited value and even harmful effect on her later 'worth', which is inherently based on her marriageability. He describes her as " twice as 'cute as Tom. Too 'cute for a woman, I'm afraid . . . It's no mischief much while she's a little un; but an over-'cute woman's no better nor a long-tailed sheep,- - she'll fetch none the bigger price for that" (56).

${ }^{26}$ The alienation of mother and daughter is a common result of the father-daughter bond in the nineteenth-century novel and is exemplified in Mr Bennet's, half-joking, yet still poignant comment to Elizabeth after he supports her rejection of $\mathrm{Mr}$ Collins - "From this day you must be a stranger to one of your parents. Your mother will never see you again if you do not marry Mr. Collins, and I will never see you again if you $d o "(110)$.
} 
emotions, but is also a form of escapism like the mill and attic, in which Maggie can retreat from the reality of other relationships.

Perhaps the most potentially dangerous of all Maggie's childhood indiscretions is her flight from home to join the gypsies. ${ }^{27}$ After pushing Lucy into the mud and being roundly condemned, Maggie's feelings of injustice and isolation reach such a tipping point that she decides to run away. Being so often likened to gypsies, Maggie comes to see their lifestyle as an escape and alternative mode of life where she will not be a misunderstood outsider. Consequently, she views the gypsy camp as a "refuge" for her to find solace, acceptance, and even distinction, as she desires to share her knowledge and become their queen (143).

The futility of her escape is signalled by the chapter's title, 'Maggie Tries To Run Away From Her Shadow,' which articulates both the inevitable failure of the attempt and the sense that what she is really attempting to run away from is an internal conflict integral to her very character, as opposed to an external force or space. When the reality of the gypsies proves unsettling and frightening, Maggie soon wishes for "Jack the Giantkiller, or Mr. Greatheart, or St. George" to rescue her and return her home (150). This wish is realised in the appearance of "some one coming on a white-faced horse" who turns out to be her father (151). Mr Tulliver is literally Maggie's knight on a white stead and his arrival inspires within her a "sudden joy" so intense it is "almost painful" (152). One of the most comforting images of the novel, like Maggie between her father's knees, is the small Maggie resting her head against her father as they ride home. Mr Tulliver's authority as the head of the household ensures that Mrs Tulliver and Tom both fall in line and no mention is made of Maggie's flight (153). In this way his relief at her safety and consequent sanctioning of her behaviour protects her from further ramifications of her actions. Maggie promises never to run away again in response to Mr Tulliver's saying she “mustn't think o' running away from father" as what "'ud father do without his little wench?" (153). Mr Tulliver provides Maggie with much needed comfort and the

\footnotetext{
${ }^{27}$ Both Emma and Mill feature gypsies as an encroaching and potentially threatening way of life. Abby Bardi comments that, "Gypsies in nineteenth-century British literature trope escape from these restrictive practices, fomenting destabilization on multiple levels throughout the texts they inhabit. Their mere presence works to overturn the conventional notions of sex, gender, and property" (113). This highlights the significance and danger of Maggie's association and potential escape with them. It also foreshadows her destabilizing narrative end.
} 
assurance that she is both a fundamental part of the familial unit and a treasured object he cannot bear to lose. However, in doing so he is simultaneously forging the ties of the past that bind her later in the novel and keep her bound to the space of the mill.

Consideration for her father is the primary force that anchors Maggie to her home, even when Mr Tulliver's legal loss, straitened circumstances and illness render it a bleak and oppressive prospect. In her flight to join the gypsies Maggie's only hesitation is leaving her father, although she quickly reasons this away with the childish fancy of sending a young gypsy to tell him she is happy and "always loved him very much" (143). As Maggie grows up and Mr Tulliver 'falls' in the world, such simplicity eludes them, but the memory of it maintains a powerful pull. Maggie's childhood is one of turbulence and tribulation, punctured by brief respites of joy from escaping to the mill, Floss, and her father. While the Floss continues, the mill and her father cannot. Her father's emotional absence during his illness isolates Maggie as she is forced to return home from school and face her new even more constricted reality. She must burgeon into womanhood and learn to properly operate in the claustrophobic domestic space of the house, where everything once familiar has altered. Maggie's turbulent emotions and forms of escapism are still intensely present but adapt and modify themselves to her new circumstance. Instead of retreating to the

physical expansive spaces of her childhood, such as the attic and corn hutch, she transforms these into internal states of comfort and disjunction from daily life. While her father's ruin signals the "golden gates" of childhood have been passed, the depiction of Maggie's formative years was not as golden or daisy-filled as either Maggie remembers it, or critics often depict it (219).

\section{The Ghosts of Maggies Not To Be Potential Plots and the Underlying Pattern of Return}

Eliot clearly delineates the way in which Mr Tulliver's legal failure, illness and disgrace act as the catalysts that propel Maggie and Tom into adulthood. The next generation are forced into new awareness and responsibility to attempt to remedy the mistakes of the old. At this crucial point of transition, Eliot heightens a seemingly conventional sense of narrative uncertainty and possibility surrounding her heroine's future. Maggie's childhood sense of isolation and being 'out of the swim' is a familiar plot device. Just as Emma's declaration she will never marry prepares the reader for 
her eventual nuptials, we have been conditioned to infer Maggie's 'otherness' will simply preface her eventual triumphant transformation. D. A. Miller gives the definition of the traditional narrative as "a distortion of what will be made straight; a holding in suspense or a putting into question of what will be resolved or answered" (272). As readers we are primed to expect that, while retaining a sense of selfhood, the disruptive and difficult aspects of Maggie's nature will eventually be 'straightened' out. The ugly duckling will inherently become a swan, or at least be acknowledged by the reader, and those most observant characters, to have been one all along. ${ }^{28}$ The unpredictability and interest in such novels is usually generated through the uncertainty of how such a conclusion will be achieved. Although Eliot seems to follow this convention, much of The Mill on the Floss's power derives from the very different conclusion in store for Maggie.

The structure of the novel enacts its central tenet of Maggie's bind between possibility and inevitability. I suggest that while playing out a series of plots which could all potentially provide fulfilment both for Maggie and the narrative, Eliot enacts in each a pattern of Maggie's return which will be the actual answer to the narrative's uncertainty. In doing so, this repeated sequence of return produces a sense of inevitability that Maggie's final return and embrace with the mill and Floss was the only possible outcome, and yet there would be no pathos if there was not at least a slight sense that perhaps one of the other plots could have satisfied and challenged her. ${ }^{29}$ For Gillian Beer the "reality of choice is crucial in George Eliot's work", but the actuality of Maggie's choice is undermined by her almost compulsive retreat back to her place of origin (Eliot 84 ).

In stark contrast to Maggie, Tom is able to flourish and follow a clear linear development after their father's failure. By first exploring Tom's narrowly defined experience, we can understand the juxtaposed and more nuanced nature of Maggie's potential paths. Eliot toys with the reader by invoking various narrative forms which could provide closure and retroactively define Maggie. Three potential plots are

\footnotetext{
${ }^{28}$ This connection is made explicit in the title of Tammy Amiel Houser's article "The Ugly Duckling' and The Mill on the Floss: A Fairy-Tale Rewriting of the Bildungsroman."

${ }^{29}$ Andrew Miller defines this concept as 'counterfactuals' in his "Lives Unled in Realist Fiction." In an observation on Dickens' writing, which speaks strikingly to Mill, he notes that "there are counterfactual lives each character is pointedly not living, defining mirror existences that have branched off along other lines than that down which he or she is, in fact, travelling" (119).
} 
presented for Maggie to achieve societal integration: the renunciation plot, the plot of vocation, and the marriage plot. While each is teased out in turn, they are necessarily discarded, and we are left with a "stalemate of alternatives" (Bodenheimer 279). Eliot presents us with the ghosts of Maggie's possible lives - a series of narrative futures that cannot be played out to fruition. While we are initially encouraged to think they could, none of these modes of being can satisfy Maggie, or unite the division in her nature. Maggie's society can provide her with no sanctioned role or position that does not stifle her nature or oppose her sense of duty. In refusing to "break the ties of the past," Maggie binds herself to the mill, her father and brother, and rejects the linear developmental and historical notion of progressing beyond them (449).

\section{Tom's Linear Development}

The Mill on the Floss ends as it began, with the unification of Maggie and Tom. The epigraph that opens the novel, "In their death they were not divided," becomes the epitaph on the siblings' grave and the closing line $(47,518)$. This conscious return to the siblings' unity implicitly invites us to compare the trajectories of the two protagonists. Eliot justified the composition of her novel by acknowledging the "three volumes will certainly have the advantage of being various" while also having "the psychological unity that springs from their being the history of two closely related lives from beginning to end" (qtd. Griest 109). Eliot presents in Maggie and Tom two implicitly entwined lives that have the same fixed beginning and end, but wildly divergent paths between these points. Maggie and Tom are both inherently drawn back to the mill, the site of their origin and childhood, but whereas Tom's experience is defined by his unwavering self-belief, Maggie's is fraught with internal conflict and division.

Much of the tension in the novel is created through Maggie's warring desire to break free and abandon the past, while simultaneously yearning to return to it. For Tom, however, news of his father's failure "awakened [him] now with a violent shock" and is a distinct turning point in his development (222). Through Maggie and Tom's responses to their father's failure Eliot depicts two competing constructions of development. Tom is "awoken from the eternal repetition which characterised childhood to an awareness of the linear nature of social time" and the "timeless world of dream is replaced by linear progression" (Shuttleworth 66). Conversely, Maggie cannot embrace such narrow simplicity and instead fluctuates between attempting to 
come to terms with her new reality and reverting back into her internal world-a dreamlike state that yearns for more. Tom begins a process of almost calcification as his life gains a clear purpose. Whereas Maggie sobs violently as she thinks of her father, Tom "felt that pressure of the heart which forbids tears" and tightens his arm around the crying Maggie with a face, "rigid and tearless - his eye blank" (223). An excess of emotion overcomes Maggie, but Tom is defined by departing emotion that leaves a cool pragmatism.

When Tom addresses the council of aunts and uncles, they are all "astonished at Tom's sudden manliness of tone" (242). Eliot clearly signals that Tom has gone through a transformation from boy to man, which is readily apparent in his new commanding manner. It is Mr Tulliver's absence and defeat that facilitates Tom stepping into this new masculine authority. Ironically, this is exactly the displacement that worried Mr Tulliver at the start of the novel and led him to educate Tom so his son would "make a nest for himself, an' not want to push me out o' mine" (61). In his new mantle as acting head of the family, Tom attempts to regulate Maggie's behaviour. He anticipates her outburst to their assembled relatives and quickly commands her to be quiet, "authoritatively, pushing her aside" (241). This moment foreshadows Tom's later exertion of paternal authority when he refuses to allow Maggie to be integrated back into the family after she returns from her trip with Stephen. However, Maggie is not so easily contained. She cannot help but take her father's 'part' like he used to for her and appeals to her aunts and uncles. However, she does so with emotive rhetoric, basing her argument on their having "no feeling" (243). Tom reveals his ability to integrate himself into a new mode by utilising a language of logic, money, and morality that he knows his maternal relatives will understand and respond to. However, Maggie is grieving for her father's situation and has no desire to mould either her thoughts or herself into a more palatable form for her aunts and uncles. She refuses to moderate the force of her feeling and consequently this interaction follows the pattern of her earlier childhood transgressions and she is once more roundly condemned for her emotional outpouring.

Tom and Mr Tulliver begin to resemble the mill that is so crucial to them as they both become reduced to automated movements. While Tom was ill-suited to academic life, his rigid and determined personality thrives as his life narrows to the singular focus of rebuilding what his father lost and restoring his family's pride and place at the mill. Like the repeated, set movements of the mill, Tom's life becomes 
characterised by the dull monotony of the business world as he labours to distinguish himself at Guest \& Co. Even once he has achieved this, Tom lacks the ability or desire to expand his world. Apart from reclaiming the mill he proclaims, "I want to have plenty of work. There's nothing else I care about much" (406). His focus and ruthless work ethic enable him to achieve his goal, but also endows him with an unsettling coolness. Tom's process of automation echoes the broken man his father has become and embodies the alienation of an increasingly mechanised society After his illness $\mathrm{Mr}$ Tulliver is likened to a machine "set to a recurrent series of movements" (301). While this serves to only emphasise Mr Tulliver's loss of spirit and passion, Tom thrives in such a mode, as he embodies the new mechanised age replacing the diminishing pastoral one. It is this fate of numb acceptance that the reader longs for Maggie to avoid.

\section{Maggie}

\section{The Renunciation Plot}

After her father's illness Maggie temporarily acquires a placid acquiescence through renunciation that is comparative to Tom's single-minded determination. However, she cannot sustain this and must return to a modified version of the dreaminess and passion that defined her childhood self. Maggie craves a source of guidance, as so far from her father providing the comfort and affirmation he used to, he has now regressed to a child-like state of reliance on her. Her discovery of Thomas á Kempis's The Imitation of Christ is consequently a welcome relief to the monotony of her days and a source of relief and inspired abstention (309). Eliot renders the discovery ambiguous by highlighting its limited temporality, as neither Maggie, nor the narrative, can sustain such a state of renunciation for long. Maggie's uncovering of the passages is presented as an awakening, much like Tom's. As she reads a "strange thrill" passes through her "as if she had been wakened in the night by a strain of solemn music, telling of beings whose souls had been astir while hers was in stupor" (310). Similar language of clear vision, insight, perception, and sudden apprehension of the solution to a persistent problem reinforces the sense that Maggie has become newly cognisant of her reality and path forward.

Maggie's physical transfiguration seems to serve as a corporeal embodiment and endorsement of her newly founded renunciation. Her "new inward life" of determined selflessness and virtue shines out of "her face with a tender soft light that 
mingled itself as added loveliness" (314). This image of an angelic light bursting forth from Maggie presents her as having achieved a divinely sanctioned apotheosis. The linking of this recent beauty 'filling in' the "outline' of Maggie's "blossoming youth" also reinforces that this new mental state aids her natural and burgeoning progression into womanhood (314). ${ }^{30}$ Her increased 'loveliness' seems to echo Tom's "sudden manliness of tone" (242). Eliot presents these as paired moments between the siblings, for just as Tom gains a new masculine force after his resolution, Maggie seems to be rewarded with an appealing femininity after her conscious renunciation.

If The Mill on the Floss were a Bildungsroman, then here, nicely tied up, would be Maggie's transforming moment of enlightenment, reflected both in her virtuous behaviour and newly acquired physical beauty. What would consequently follow would simply be the unfolding of her renunciation and selfless ministering to the needs of others. Maggie appears to have achieved both the inward peace and outward validation that eluded her as a child. She gains this approval, particularly from her mother, predominantly through her ability to now function as an ornament. As a child, her delicate cousin Lucy threw Maggie's boisterous vibrancy and gypsylike appearance into sharp relief but now Maggie's renunciation creates a partial transformation into a similar doll-like creature. She has acquired a shining beauty, patient submissiveness, and the ability to sit peaceably (314). Her mother even delights in fashioning Maggie's hair, those tresses which she had "trouble enough with . . once," into a regal coronet, signifying that what was once wild has now been tamed (314). This domestic routine between mother and daughter seems to indicate a development from their previous discord to a new harmonious unity that could typify Maggie's new life. Furthermore, Maggie's eyes which used to flash and flare, now seem to have an almost healing and soothing power as her mother waits for Maggie's glance, "as if her elder frame got some needful warmth from it" (314). The raging fire appears to have been harnessed and channelled. This scene evokes a sense of calmness and closure indicating Maggie's transcendence from the unfulfilled passions and desires that plagued her childhood. And yet, like Austen, for Eliot the stagnation

\footnotetext{
${ }^{30}$ Maggie's physical transformation at the time of her newly achieved docility speaks to an earlier, and still persistent, narrative association between female beauty and goodness. Juliet McMaster notes that Eliot, among other women novelists such as Frances Burney and Charlotte Brontë, "is resisting the male tendency to exclaim, 'Behold the first in virtue as in face!'” (Body 66).
} 
and sleepiness implicit in such a transformation render this plot an overly simplistic and unsatisfying answer.

The renunciation plot cannot provide Maggie with a fulfilling future as her yearnings and passionate nature are repressed by it rather than addressed or utilized. Even at the peak of her selfless determination, her "new inward life" is described as being tranquil, "notwithstanding some volcanic upheavings of imprisoned passions" (314). Maggie's renunciation is consequently not a pinnacle of character development, but simply an altered state, while her true turbulent nature remains repressed. If Maggie continued in her vein of renunciation, the novel would reach an impasse. Her mother wonders- "It was amazing that this once contrairy child was become so submissive, so backward to assert her own will" (314). Her path of denial cannot continue as her volcanic upheavings are incapable of remaining dormant and she must express them and revert to her earlier state.

Maggie's renunciation could be viewed as D. A. Miller's 'straightening' out of her wayward character into domestic and submissive virtue; however, Eliot cannot endorse such a transformation at the cost of Maggie's individuality. Woolf notes that Eliot's heroines utter "a demand for something - they scarcely know what - for something that is perhaps incompatible with the facts of human existence" (217). In The Mill on the Floss Maggie yearns for an external life that aligns with and accepts her internal one and this is precisely why her devotion to renunciation cannot succeed. While her renunciation prompts the familial affection and approval she previously lacked from those other than her father, it is based on the rejection of her fundamental identity. Kempis's call is to "Forsake thyself, resign thyself, and thou shalt enjoy much inward peace .. Then shall all vain imaginations, evil perturbations, and superfluous cares fly aware; then shall immoderate fear leave thee, and inordinate love shall die" (310). However, Maggie's vivid imaginings and 'immoderate' passions are integral to her character and thus they cannot be sacrificed for a transitory sense of tranquillity. Maggie later reflects on this period of renunciation and recoils from the memory of its "negative peace" (394). She cannot be long satisfied with the repression of her true self, in the same way that the narrative could not sustain a plot based on negative fulfilment. 


\section{The Vocation Plot}

Given the novel's ostensible purpose of presentating Maggie and Tom's transition from youth to maturity, the lack of any description of Maggie's significant periods of absence from Dorlcote Mill and St Oggs is a glaring omission. Maggie leaves home for an extended period first for her schooling with Lucy and then again after her father's death when she spends almost two years as a country schoolteacher. Elizabeth Carolyn Miller notes that "the temporal arc" of the novel is "curiously bifurcated, with the first part focused on Maggie Tulliver's childhood and the later part focusing on her young adulthood," ignoring what occurs in the interim (86). ${ }^{31}$ What makes this omission all the more unusual is that both of the unnarrated phases in Maggie's life centre on education. From childhood, Maggie has been presented as a precocious and voracious reader. She loves to demonstrate her bookish knowledge, from trying to impress Mr Riley with her nuanced understanding of the morality of Defoe's History of the Devil and Pilgrim's Progress to teaching the gypsies about Columbus (62-63, 147-148). Moreover, while Tom rebels from his classical schooling and the rigours of Latin declensions, young Maggie inherently takes to them and we are encouraged to see that it is her nature, not his, that would excel in this academic realm if her gender did not inhibit her. ${ }^{32}$ Given the novel seems to take great pains to repeatedly emphasise Maggie's bookish and pedagogic strain, its refusal to entertain the possibility of her enjoyment and fulfilment as pupil or teacher is conspicuous.

While I find the plot of education and vocation the most persuasive in terms of possible fulfilment for Maggie, the novel refuses to seriously consider it. Maggie's time at Miss Firniss' school is mentioned only in passing, and her stretch as a country teacher is only given slightly more detail. Far from being an enriching and stimulating experience for Maggie, it is depicted as weary and claustrophobic. In contrast to the roast dinners and easy opulence of Mr Stelling's household, Maggie's time as a

\footnotetext{
${ }^{31}$ Deanna Kreisel also sees the novel as being "conspicuously silent about the austere intervening years Maggie spends as a teacher, which might certainly warrant attention given the narrator's supposed concern with her developing spirituality and quietism" (92).

32 Maggie's inability to achieve an academic future is even more striking given her creator did. Eliot's first biographer, Mathilde Blind, expresses what came to be a common observation on Eliot and her heroines- "It is certainly curious that the woman, who in her own life had followed such an independent course, severing herself in many ways form her past with all its traditional sanctities, should yet so often inculcate the very opposite teaching in her works" (88).
} 
teacher is characterised by "watery rice-pudding" and the thankless servitude of mending young girls' clothes $(172,383)$. Eliot refuses to depict an idealised community of learning that would sustain Maggie but instead gives glimpses of what appears to be another form of intellectual and emotional starvation for her to endure. On her return from teaching Maggie likens herself to a trapped circus bear that has "got stupid with the habit of turning backward and forward in that narrow space," again echoing the repetitive movement of the mill (383). In contrast to her childhood where she could run freely alongside the Floss, Maggie's more recent experiences leave her feeling trapped and cloistered. Her original hunger for a place of belonging, expansive experiences and open spaces is only amplified. Whereas Tom's vocation imbues him with purpose and linear development, Maggie's only serves to further repress her yearning soul into mundane repetition and narrow confinement that leads her back to her childhood desires.

The novel's omission of depicting Maggie's periods away at school, as both pupil and teacher, only emphasises her return home from these experiences. The effect of the conspicuous silence on Maggie's movement in different spheres is that she only exists for the reader in the space in which we first meet her. We are not given a plot like Jane Eyre that depicts her experiences as both student and teacher immersed in different schools, households, and communities, tracking her own development and confirming more clearly to the Bildungsroman form. Instead, while we are dimly aware that she has been elsewhere, we do not see Maggie operating in any other environment than her original one. In fact, so little detail is given, or mention made of her time elsewhere that it is as if we are supposed to merely forget it. Maggie's departure is never described, but her return after both periods away is. Consequently, her movement is restricted to the mill, St Oggs, and the Floss, and it is as if she cannot truly exist outside these sites. Read in this light, Maggie's refusal to leave St Oggs after her disastrous excursion with Stephen and consequent social ostracism, which at first glance seems perverse and almost masochistic, is in keeping with the spatial logic of the novel. Just as Mr Tulliver cannot leave the Mill after his disgrace, neither can Maggie. The novel includes Maggie's education and employment as a teacher but Eliot's decision to withhold meaningful depictions of these experiences amounts to a refusal of the vocation plot. 


\section{The Marriage Plot}

With the dismissal of both the renunciation and vocation plotlines, the narrative turns to the cornerstone of nineteenth-century literature - the marriage plot. For many readers, Maggie's turbulent childhood and phases of renunciation, education, and vocation likely seemed only the preparation and preface to her eventual nuptials. For most nineteenth-century heroines, marriage provides closure to their tale not only as it is the culmination of the romance plot but because it "is the symbolic event which represents the achievement of the goal, the completion of the quest for maturity" (Ralph 2). While there has been the potential from early on in the novel that Maggie will find herself in a 'companion' marriage with Philip, a hybrid form of her religious renunciation and desire for further education, it is not until Stephen's entrance that the narrative seems to invest tangible passion and possibility into the marriage plot. The reader seems to be encouraged to predict this traditional marital end given the chapter in which Maggie and Stephen meet is titled 'First Impression,' an echo of Austen's original title to Pride and Prejudice, which famously ends in the harmonious marriage between hero and heroine.

Maggie's interactions with Stephen are characterised by intense and overwhelming feelings that almost paralyse her in their force and render rational thought difficult. However, what Maggie is engaging with, rather than a clear perception of the man himself, is her own hazy construction of him and the very ardent feelings he invokes. This distinction is what undermines the validity of Maggie and Stephen's potential union. Critics, such as W. J. Harvey have criticised the last section of the novel, particularly the vague and unrealized depiction of Stephen (123124). There is certainly a sense that he is hardly invested with enough brilliance or sympathy to be a worthy match for Maggie. In response to Harvey, Nina Auerbach persuasively proposes that for her, the "fractured rush of events" between Maggie and Stephen is fitting as "the action is presented as Maggie lives and perceives it" (152). Stephen's 'sketchiness' is consequently not an artistic failure on Eliot's part, but a triumph, as it deliberately reflects Maggie's "perception of him as less a whole man than a smell, a hand, a soothing voice, and the promise of ease in an unhappy life" (152). The subordinate position of Stephen to what he represents and the emotions he elicits is apparent from Maggie's contemplation the night after their first meeting.

It was not that she thought distinctly of Mr. Stephen Guest, or dwelt on the indications that he looked at her with admiration; it was rather that 
she felt the half-remote presence of a world of love and beauty and delight, made up of vague, mingled images from all the poetry and romances she had ever read, or had ever woven in her dreamy reveries.

The indistinct and hazy nature of Stephen himself and the contrasting, immediate presence of Maggie's own imaginings of romance and ease define their interactions more and more as the novel progresses. On that same first night, Maggie briefly reflects on the time she spent in dedicated renunciation and as a teacher; however, memories of the evening break in on her thoughts and "she could not stay the recollection of that bare, lonely past. She was in her brighter aërial world again" (394). This "brighter aërial world" is reminiscent of her times in the attic and corn hutch of the mill as a child, and we see how Maggie has internalised these elevated physical sites of exultation and freedom into her own inner world. It is this world, enlivened by abstract visions of romance, that Stephen inspires, but does not truly enter. Just like her childhood, Maggie is soon conflicted by the harshness of reality and her desire to escape into a world of heightened emotion and fantasy where she can indulge in her unsanctified compulsions. Maggie is once more trapped in a cycle where the internal and external refuse to align. While Maggie will submit to the drive of the marriage plot when she drifts down the river with Stephen, she breaks free, and once more returns home.

What becomes readily apparent is the manner in which all three of Maggie's potential plots resemble each other in their essentials. Rachel Ablow notes that á Kempis "affects Maggie in a way that closely-and necessarily suspiciouslyresembles Stephen's influence," as they both compromise Maggie's autonomy of thought and action (84). And in an echo of Maggie's physical blossoming after her decision to follow a path of renunciation, when Maggie meets Stephen there is a "new brightness in her eyes, and a very becoming flush on her cheek" (385). These are simultaneously the clichéd markers of romantic attachment, encouraging the reader toward that end, and the repeated outward indications of her soul reawakening from its deprivation and repression. Thus, this is revealed to be another phase in Maggie's cycle of awakening and attempting to find another outlet for her turbulent emotions, like the water channelled through the mill, rather than a final end point. While á Kempis, education in various forms, and Stephen all seem to potentially provide a linear development and fulfilment for Maggie, each is revealed to be insufficient and 
only a modified form of her childhood emotional escapism. Maggie "never grows away from her capacity to plunge into the moment, to submerge herself exclusively in what is near" (N. Auerbach 151). However, each of these plots results in a transitory submergence that cannot be sustained, and Maggie inevitably returns back home to the mill as the glimmer of another possible plot is extinguished.

Maggie's refusal of these plots means she is not retroactively defined by them. The rejection of these plots denies the retroactive imposition of order or tradition over Maggie's personality. Moretti describes how in the Bildungsroman form, "the meaning of events lies in their finality" (7). By subverting this teleological formulation, Eliot renders the events of Maggie's life meaningful on her own terms. For example, if she married Stephen she would be primarily defined as a wife and her development, and the novel, would be categorised as a marriage plot. The absence of this definitive, conventional ending places the emphasis on her development itself, as opposed to the conclusion shaping it after the fact. As Jerome Buckley notes, The Mill on the Floss "describes the beginning of a life necessarily still incomplete; and its interest and power lie in the unfolding of that life rather than in the end imposed upon it" (115). The novel's conclusion enshrines Maggie's development on its own terms but also renders her end powerful in both its emotional intensity and the way in which it is the logical completion of her pattern of return that has been established throughout the novel.

\section{The Final Return}

\section{Maggie's Union with the Floss}

The Floss is described as "backward-flowing" and "backward-rushing" twice in the novel. First, to describe the manner in which Stephen is aided by the current as he rows Maggie too far down the Floss, and second, to depict the water Maggie is blankly staring at before Lucy visits her, which is then followed by 'The Last Conflict' that ends the novel $(467,506)$. The change from 'flowing' to 'rushing' indicates the narrative's increased energy as it hastens towards its dramatic end. This seeming paradox of the tide rushing on, but inherently moving backwards, exemplifies Maggie's movement, both mental and physical, throughout the novel. She returns not only to the mill, but to her childhood state of conflicted and turbulent emotion as she fails to find a future to sustain her or unite the division in her nature. With no channel for her energy, she is necessarily brought back to the past. Elizabeth 
Miller notes that the novel's conclusion is "poised between the future and the past, reading them in relation to each other" (94), which echoes Esty's claim that at the novel's heart is the idea of Maggie being "permanently suspended at the threshold of committed and constrained womanhood" (116). Even though the narrative cannot sustain this state of suspension, Miller and Esty acknowledge the sense that in The Mill on the Floss Eliot is attempting to prolong the moment of transition- the point of possibility where nothing is yet decided. Maggie's moment of suspension also mirrors that of her society in the novel, which is poised between an older rural way of life and the encroaching mechanisation and urban mentality.

Eliot achieves the sense of deferring Maggie's transformation into adulthood through the intense meditation on Maggie's childhood and the repeated refusal of various plots which would have provided her young protagonist with a concrete and continued future. Instead of moving forward into the unknown, the novel consistently brings us symbolically back to that moment of indecision and yearning of the young Maggie poised in the parlour doorway looking at her empty chair. However, this moment inherently cannot last. Just as the novel's narrator describes "the onward tendency of human things," so too must the narrative go on (294). Eliot's solution to this dilemma is to take Maggie forward, but through returning to the past, like a 'backwards-flowing tide.' Therefore, while the novel's notorious ending of Maggie's drowning has a long critical tradition of being viewed as a narrative failure, it can certainly be read as an aesthetic and structural success for the manner in which it is the decisive culmination of Maggie's repeated pattern of return that has shaped the novel.

Like Emma, since its inception, The Mill on the Floss's dramatic conclusion has produced impassioned and divisive responses. Henry James famously decries the novel's end due to structural objections:

what I object to, is [the flood's] relation to the preceding part of the story. The story is told as if it were destined to have, if not a strictly happy termination, at least one with ordinary probabilities. As it stands, the denouement shocks the reader most painfully. Nothing has prepared him for it; the story does not move towards it; it casts no shadow before it. $(30-31)$

As I read the novel, the flood casts a rather substantial shadow before it. Eliot deliberately dispenses with 'ordinary probabilities' of narrative termination, and 
nothing could be more prepared for by Maggie's constant cycle of return home to the mill and her affinity to the turbulent Floss. Critics have predominantly responded to James's claims by noting how flooding and drowning have in fact been thoroughly foreshadowed by numerous references and images embedded prior in the narrative. ${ }^{33}$ Nathan Hensley acknowledges both positions with his concept of 'reading The Mill on the Floss backwards' and proposes that the ending is structurally impressive being "at once a spectacular rupture with the protocols of fictional probability and their perfect fulfilment" (128). I agree with Hensley and would add that Eliot's achievement of this paradox and ability to create such an impassioned and conflicted response from readers is itself a success that reflects the dichotomy of Maggie's situation. There is a feeling of loss that she could not live out one of the potential plots presented to her, and yet if she had, the novel would necessarily end on a note of inadequate female compromise, as Eliot's later novel Middlemarch has been read by many as doing.

Maggie's refusal to conform to a domestic ideal at the cost of her life naturally invites a rather fraught feminist reading. Maggie is part of a tradition of heroines, such as Catherine Earnshaw, Tess Durbeyfield, and Emma Bovary, who all yearn for more from life only to lose it. The death of these women seems to be a punishment for their transgressions and inability to integrate themselves peacefully into a societal, and thus narrative, order. Maggie's refusal to compromise her morality and worldview with society's, epitomized in the novel by the condemning opinion of "the world's wife" (48), abandons "the dialectic of reintegration" that sustains the female Bildungsroman (Ellis 10). Consequently, Maggie's end has been read as a subversive triumph through her refusal to submit to the restrictive, domestic feminine ideal that has plagued her since childhood. However, the sense of triumph is undercut in this reading, as it appears to be only achievable through death. Maggie's death can be seen as a failure to unite the disparate parts of herself. Bonnie Zimmerman posits that Maggie kills herself "in a battle with the 'other woman,' that preferred feminine exemplar" which she has "failed to become" and the there is an implicit critique on the inability of her society to let her be otherwise (169).

The renunciation plot seemed to indicate Maggie's transformation into a domesticated and submissive ideal. Similarly, the novel explicitly confirms that had Maggie married Stephen she would have been enfolded into society and continued the

\footnotetext{
${ }^{33}$ See John Rignall's Oxford Reader's Companion to George Eliot (266).
} 
'queenly' influence over the inhabitants of St Oggs that she briefly achieved in her time staying with Lucy. Nevertheless, Maggie rejects both these feminine roles, which would have endowed her with a stable place in society and the sense of belonging she always craved. However, what is often ignored by critics, and complicates this simplistic feminine binary of inclusion and exclusion, is the significant female solidarity later exhibited by Mrs Tulliver and Aunt Glegg. When Maggie returns home after her absence with Stephen she is shunned by Tom and her community. And while her mother and Aunt Glegg were the most oppressive figures of her childhood, constantly disappointed and disapproving of her inability to conform to the Dodson female ideal, both stand by her when others do not. Her mother movingly promises to accompany her when Tom refuses to allow her entrance back home and Aunt Glegg roundly condemns him for his lack of faith in Maggie (484, 496-497). Thus, while Eliot does not dwell on these moments, their presence provides an understated source of female kinship and solidarity amongst her condemnation of the restrictions and double standards placed on female development.

Maggie's two most significant returns to the mill form the crux of the novel and accentuate her developed autonomy. The first of these is Maggie's controversial return home after her indiscreet flight with Stephen, which occurs in a chapter aptly titled "The Return to the Mill". The novel's pattern of return complicates the issue of Maggie's autonomy - it is often unclear whether Maggie actually desires to return or is inevitably compelled to, like the trapped circus bear. Yet, in this moment, Maggie clearly makes a choice against what seems like logic and all other factors to come back home. ${ }^{34}$ Maggie's trip down the Floss with Stephen is problematically depicted not so much by her agreement but by a hazy yielding both to his compulsion and perhaps the unconscious lure and apparent ease of the marriage plot. Conversely, her decision to return is depicted as a harsh awakening to reality and is the result of a conscious and thorough assessment of her situation and duty to the ties of the past. This time Maggie is not rescued by her father on a white horse but must instead liberate herself and make the difficult journey home alone. This empowerment is further developed in her final return to save Tom from the flood. For now, her return is not a loving enfolding back into the familial unit, as when she was younger, but is met with rejection and dismissal. Like the prodigal son in Luke's drawings she used

\footnotetext{
${ }^{34}$ Although, as previously mentioned in 'The Vocation Plot' section, this decision is in keeping with the spatial logic of the novel given her pattern of return.
} 
to observe, Maggie returns home "for refuge," love, and acceptance, but is met with a brother's disgust as opposed to a father's forgiveness (481). In the culmination of his increasing narrowness and process of automation, Tom uses his paternal authority as head of the family to renounce Maggie saying, "You will find no home with me" (481).

Tom deliberately invokes Mr Tulliver, who always rejoiced in Maggie's presence, as a weapon against her- "You have disgraced us all. You have disgraced my father's name" (483). In a symbolic act of primogeniture, Tom's use of "my" instead of "our" acts to claim Mr Tulliver for himself and further severs Maggie from both the memory of their father and the family as whole. His further outburst, "You don't belong to me" recalls Lawyer Wakem's claim that a woman is not defined by her actions, but "whom she belongs to" (483, 432). ${ }^{35}$ However, like his earlier attempts to restrict her, Tom can never completely contain Maggie. While they certainly have an intense bond, Tom does not have the same power over Maggie as Mr Tulliver did because he lacks the same accepting emotional connection. As Maggie says to Tom earlier in the novel, "I will submit even to what is unreasonable from my father, but I will not submit to it from you" (362).

Maggie's final return home in the flood justifies and completes the pattern of return throughout The Mill on the Floss by providing the unification she always yearned for. In the moments before the flood Maggie is revisiting the various stages of her life and the possibilities she could have followed-she reflects on her hollow time of renunciation and is torn how to answer Stephen's plea for her (507-512). This internal revisiting reflects the increased turbulence of her nature from her recent harsh treatment and her current emotionally starved state. Maggie "was again sitting in her lonely room, battling with the old shadowy enemies that were forever slain and rising again" (507). Whereas, as a child, Maggie thought she could run away from her shadow, she has now come to accept the seemingly constant cycle of discontent and the division of her nature. However,

\footnotetext{
35 Tom's disowning of Maggie is directly opposed to the reactions of her mother and aunt. Mrs Tulliver says, 'My child! I'll go with you. You've got a mother" and Aunt Glegg "only hoped that Mrs Wooll, or any one else, would come to her with their false tales about her own niece, and she would know what to say to that ill-advised person!"' (497). Their language is one of inclusion, ownership and reclamation that refolds Maggie back into the family. Therefore, in the face of Tom's patriarchal rejection, Eliot provides a glimmer of hope in the sense of female kinship and solidarity.
} 
At that moment Maggie felt a startling sensation of sudden cold about her knees and feet: it was water flowing under her. She started up: the stream was flowing under the door that led into her passage. She was not bewildered for an instant-she knew it was the flood!

The tumult of emotion she had been enduring for the last twelve hours seemed to have left a great calm in her (512)

As soon as the Floss touches Maggie's feet she feels a sense of transcendent peace. Maggie's "tumult of emotion" has never been replaced by "a great calm" so swiftly and to such an extent through any other interaction or experience in the novel. Maggie's relationship with the water is an intensely conscious and cognisant one, almost like the inherent recognition of a loved one's touch, all confusion vanishes and "she knew it was the flood" (512, emphasis mine). Whereas Maggie's previous experiences have been defined by hunger and yearning, followed by uncertainty and dissatisfaction, here, finally, is a moment of surety in her somatic recognition of the flood. Maggie's consequent navigation of the dangerous waters reflects the tranquillity that comes from her complete belief in her course of action. Tom's 'old' utterance of "Magsie" expresses perhaps his eventual understanding and appreciation of his sister and her response is again one of longed-for unity as she utters "a long, deep sob of that mysterious, wondrous happiness that is one with pain" (516)

While most critics focus on the ending's explicit emphasis on Tom and Maggie's union in their drowning embrace, the flood unites Maggie with much more than just Tom. Their graves are located near "the brick grave that held a father whom we know"; both siblings are thus finally reunited with the father whose presence lingered long after his death (517). But more importantly, Maggie has finally and decisively returned home. Woolf notes of an Eliot heroine "the place where she stands in aspiration and agony is the heart of the book-still and cloistered like a place of worship, but that she no longer knows to whom to pray" (217). However, when the water first touches Maggie she knows exactly what to pray to, and it is the very 'place where she stands.' Wakem asks the wrong the question - it is not to 'whom' a woman belongs in this instance-but to 'what'. It is in the Floss that Maggie finds her belonging and unification. While I am not undermining feminist readings of the novel, which importantly critique the novel's affirmation of female autonomy being achieved only through death, I suggest that it is vital to consider the manner of that death. Maggie's drowning acts as the marriage of the novel, uniting her with the 
object of her desire from the very first page. Where the young Maggie stared intently at the mill and Floss, the final page sees her union and complete submergence within it. Although this is clearly a romanticised reading of the novel's conclusion, it is in keeping with the romantic mode Eliot is operating in for this final section. Critics have often noted the "Romantic register in which Maggie's death is presented" (Guth 159). Eliot is often compared to Wordsworth, and her integration of her heroine with nature is a very Wordsworthian one. ${ }^{36}$ This romantic and pastoral reading is thus fitting, given it is the culmination of Maggie's cyclical movement that has structured the novel. Kermode notes that "we use fictions to enable the end to confer organization and form on the temporal structure," and this is what Eliot achieves in Maggie's final return (45).

Whereas an older and more mature Eliot will later explore conclusions of more conventional paradigms of female compromise and integration with nuance and sophistication in Middlemarch, The Mill on the Floss is the younger novelist's raw and impassioned refusal to do so. In Maggie, she created a character whose ardent energies could not be contained by her society or traditional narratives of female fulfilment, and endowed her with a suitable spectacle of a conclusion: "Maggie's intentions, as usual, were on a larger scale than Tom," and perhaps the James-like reader, "had imagined" (143). Eliot is insistent on the bonds of sympathy and duty that exist between characters, but while her ties to the past entwine Maggie, she cannot maintain or be sustained by them. Instead, she is united with the only other force as turbulent as she, and which she has existed side by side with all her life. Just as the flood bursts its bounds and overcomes all efforts to control or dam it, so to does Maggie overpower the narrow channels her society laid out for her. The novel had a number of potential titles, including "Sister Maggie" and "The House of Tulliver." And although both emphasise the significance of Maggie's familial ties, the final “The Mill on the Floss" acknowledges Maggie's true home. The novel's conclusion continues the sense of cyclical time, refutes linear development, and echoes the pastoral transience of the opening tableaux. Nature has "repair[ed]" her ravages, the Mill and churchyard are "rebuilt," the grass over Mr Tulliver's grave has "recovered" and Maggie is felt to be a "revisiting" spirit (517-518). And while the cyclical nature of time is implicitly contrasted with the permanence of Maggie and Tom's deaths, the

\footnotetext{
${ }^{36}$ Eliot wrote of Wordsworth: "I never before met with so many of my own feelings expressed just as I could like them" (Letters 61).
} 
"uptorn trees are not rooted again", Maggie has found her place of belonging and returned home for the final time (517). 


\section{Stepping Into the Unknown}

\section{Beyond Hearth and Home in Persuasion and Middlemarch}

"It is felt that men are henceforth to be held together by new ties, and separated by new barriers; for the ancient bonds will now no longer unite, nor the ancient boundaries confine" - J. S. Mill, "The Spirit of the Age" (1831)

One of the central aims of this thesis is to reclaim the validity and importance of the heroine who stays behind and 'tends the home fire'. Emma and Mill illustrate that physical progression or relocation is not the sole indicator of personal or societal growth. However, a striking detail in both novels is the presence of a baby named after the heroine, who will implicitly become a more mobile figure than her namesake. Isabella names her newborn after her sister, and through living in London and travelling to Hartfield, baby Emma has already travelled a significant distance in the novel's terms and will likely continue to do so. She will also be immersed in the bustling life of the city as opposed to the quiet life of Highbury. Emma herself alludes to this sense of potential generational progression in her half-joking advice- "Little Emma, grow up a better woman than your aunt" (95). ${ }^{37}$ Similarly, Bob Jakin, arguably the most mobile figure in Mill given his profession as a wandering packman, names his baby after Maggie, and she can be expected to lead a life beyond the bounds of St Ogg's as her father does. Rachel DuPlessis observes that the ends of some novels are "inspirational, sublimating the desire for achievement into a future generation, an end for female quest that was not fully limited to marriage or death" (“Ending” 282). While Maggie and Emma decisively achieve fulfilment and success on their own terms, in the subtle undertone of the babies' names, both novels channel their remaining desire for increased female movement into the next generation. Austen and Eliot's later novels, Persuasion and Middlemarch, have no need for such a narrative device, as the heroines themselves come to embody this state of heightened adaptability and mobility.

\footnotetext{
${ }^{37}$ Perhaps the most famous nineteenth-century incarnation of this pattern of intergenerational development is Emily Brontë's Wuthering Heights (1847), which sees a heroine named after her predecessor and what has often been read as a second generation atoning for the sins and remedying the mistakes of the former.
} 
The later novels still focus on the heroine's development but they loosen her ties to the past to render her a more mobile figure. Anne Elliot and Dorothea Brooke are both in a more mature phase of life than the earlier heroines-Persuasion opens years after Anne first meets Wentworth and Dorothea marries Casaubon before being later united with Will. Consequently, they are contending more with mature pasts of their own creation, rather than those of childhood. Austen depicts the Elliots as regressive, self-centred and stagnating, and consequently an undesirable state for Anne to return to. Eliot achieves a similar result by providing Dorothea with no significant familial relationship to influence or define her. Neither heroine has a fulfilling and affirming relationship with her father and both are therefore able to forge ties of their own without attempting to also accommodate a paternal figure. Unlike Emma and Maggie, they move beyond the familial home and exchange their position as part of the landed, rural gentry to instead immerse themselves in a more dynamic and democratic group of individuals. Anne's ending at once provides closure on the level of the marriage plot while concurrently cultivating a sense of uncertainty and possibility surrounding her future as a naval wife. Middlemarch has been critiqued by scholars unsatisfied by Dorothea and Will's union, but Eliot utilises it to convey Dorothea to the bustling metropolis of London and the "incalculably diffusive" effect she can have there (785). Both heroines consequently seek and find their meaning in their future rather than their past.

Anne and Dorothea's personal transitions are accompanied by a sense of heightened scale and a more explicit delineation of the evolving socio-political landscape than is found in the earlier novels. Eliot wrote of Mill's conclusion that she was "beguiled by love of [her] subject" into the "Epische Breite"- the "epic breadth' - and Middlemarch published eleven years later realizes this desire from its initial pages (385). Middlemarch creates a sense of vastness in the web of characters whose consciousnesses comprise its structure and Austen generates a similar feeling of expanse in Anne's relocation to various households and cities. ${ }^{38}$ Emma and Mill present heroines who remain at home and societies only beginning to adjust to a new social order. The seeds of change only becoming visible in the earlier texts have grown and become much more prominent in Persuasion and Middlemarch. Unlike their predecessors, both are set in an explicit historical moment, and they depict

\footnotetext{
${ }^{38}$ See also Bruce Stovel's "Subjective to Objective: A Career Pattern in Jane Austen, George Eliot, and Contemporary Women Novelists."
} 
communities facing change on a much more confronting level. Anne and Dorothea's personal progressions from rural gentlewomen to wives in the city or on the sea are consequently imbued not only with the interest of a marriage plot or Bildungsroman but have the added significance of echoing the passage of their societies in the midst of turbulent transition.

\section{Persuasion--the "natural sequel of an unnatural beginning" (29)}

At the conclusion of an Austen novel, the heroine is not only united with her hero, but is also firmly situated in a home which both stands in for and sets the scene for the new phase of life she is about to enter. Be it a large manor house, like Pemberley or Hartfield, or a parsonage such as Woodston or Delaford, the home provides a concrete and solid location to secure and shelter the heroine. Austen's last completed novel, Persuasion, is the only exception to this rule. The novel tracks Anne's progression from the well-established yet stagnant Kellynch Hall, through to Uppercross, Lyme Regis, Bath, and finally to no reassuringly named manor or parsonage, but instead the unknown destinations of her future as a naval wife. Already this geographic expanse is a world away from the confined shrubberies of Hartfield. From its beginning, the novel works to quicken our realisation that this outcome of uncertainty is in fact the only one to ensure Anne's happiness and continued growth. The ending is consequently a conscious explosion of Austen's past narrative pattern and any sense of security arising from pre-existing physical structures and an aristocratic value system predicated on land and tradition. This innovation is implicitly tied to another-namely that Persuasion is the only novel Austen set within a specified historical timeframe. It opens in the "summer of 1814", a period of peace and the presumed end of the Napoleonic Wars and closes in late February 1815, just on the cusp of Napoleon's escape from Elba (10). Anne's individual transformation is consequently set at a very specific moment of significant national change.

The central dilemma of Emma and Mill - the heroine's negotiation of her past and future in attempting to reconcile her family and childhood with the prospect of a fulfilling future of agency - is also at the heart of Persuasion, but the parameters have shifted. Whereas Emma effectively remains confined at Hartfield and Highbury, Anne is almost immediately transplanted from her family home to a whirlwind of new households and environs. The instability and burgeoning change that was just beginning to make ripples in Emma with encroaching gypsies, robbed poultry houses 
and the upward social mobility of figures such as Mrs Elton and the Coles, has now taken centre stage in Persuasion and culminated in the forced removal of the Elliots from Kellynch Hall and their replacement by the Crofts. This substitution foreshadows Anne's similarly momentous transformation from landed gentry to naval wife. Her development is consequently imbued with much more of a sense of historic and political urgency than that of any of Austen's earlier heroines - as she leaves behind the slowly decaying aristocracy for the dynamism and uncertainty of the navy. Indeed, the intense necessity for socio-political change seems to account for the radicalness of Anne's personal transformation. ${ }^{39}$ Her entry into this new future and burgeoning meritocratic social reordering is predicated on her mobility and regained selfhood, which can only begin to be realised once she leaves Kellynch Hall. The vitality and potential of the specific historic moment allows for transformation, but only through a shedding of the detritus and ineffectual trappings of the past. Austen begins this process as her heroine steps out from Kellynch Hall and away from her family who embody the sterility and stagnation of their class.

The absolute necessity of change, both for Anne and the English sociopolitical landscape, is violently impressed upon the reader by the bleak and restrictive depiction of Kellynch Hall and its master in the novel's opening pages. Whereas both Hartfield and Dorlcote Mill can be oppressive environments for their respective heroines, they also meaningfully sustain and provide them with a sense of home and belonging. This sense of 'home' is predominantly generated by the presence of $\mathrm{Mr}$ Woodhouse and Mr Tulliver, whose adoration and pride in their daughters play an affirming role in the construction of their identity. Conversely, Anne is quite literally a 'nobody' to her father. In her features "there could be nothing in them, now that she was faded and thin, to excite his esteem" (7) ${ }^{40}$ Combined with the grief of losing a beloved mother and fiancé, and her stagnant daily surroundings which have remained unaltered since these losses, Sir Walter's distaste and disinterest actively hollow out Anne's person till there is 'nothing' in her. So far from being an affirming and validating force, Sir Walter reduces Anne to a nonentity, someone with "no weight"-

\footnotetext{
${ }^{39}$ Rebecca Posusta calls Anne's growth "nothing short of astounding” and even goes so far as to claim her as "the one character of all Austen's creations who makes a clear and total physical, emotional and social transformation" (89).

40 This sense of being 'nothing' to her father is cruelly echoed when she finally meets Wentworth again and reflects on the hollowing out of their relationship- "Once so much to each other! Now nothing!" (59)
} 
a "non-representation" (Young 82-83). ${ }^{41}$ This process is reflected narratologically by Anne's "unacknowledged physical presence" and infrequent direct speech in the first chapters of the novel (Morris 160). It is readily apparent from the opening pages that she must find acceptance, fulfilment, and change somewhere other than her home. Like breaking a fairy-tale curse, Anne must pass the boundary of Kellynch Hall to regain voice, body, and sense of self.

Sir Walter and Elizabeth Elliot cling to a crumbling ideal of aristocratic hegemony and repeatedly perform a dangerous denial of time, change, and physical reality. Sir Walter is the epitome of his own ideal and consequently can neither desire nor enact meaningful change. Like the ouroboros eating its own tail, vanity "was the beginning and the end of Sir Walter Elliot's character" and the sense of solipsistic circularity and stagnation evoked by this evaluation is a decisive indictment against his ability to evolve (6). Similarly, his daughter Elizabeth "has frozen into a female simulacrum" of her father, "mirroring and reinforcing his narcissism" locking them both in a cycle of "sterile self-admiration" (Beer, Persuasion xv). Sir Walter's obsession with mirrors reflects not only his vanity but also his complete lack of perception or interest in anything that does not place him at the centre. Through Sir Walter and Elizabeth, Austen condemns the empty pageantry of aristocracy that bases its judgments on appearance rather than substance. More subtly though, she illustrates how Sir Walter and Elizabeth's desires and satisfaction in their own images distorts their physical reality. Elizabeth smugly congratulates herself on their Camden Place house "boasting of their space" despite it consisting of "two walls, perhaps thirty feet asunder" (129). More disturbing is Sir Walter's belief that his favourite Mrs Clay has miraculously effaced her affronting freckles, when it is clear to Anne no such change has occurred (137). Elizabeth and Sir Walter's reshaping of their physical environment to suit their deluded self-image and fantasies reveals the extent of their solipsism and complete inadequacy to contribute to their society or community in any meaningful way.

Critics have often noted Persuasion's endorsement of meritocracy over the aristocracy but what has been unobserved is the manner in which the novel itself

\footnotetext{
${ }^{41}$ Fiona Stafford explains Anne's reduced status as a matter of vision - her "existence is circumscribed by her family, but if she perceives her nothingness beyond, she is equally conscious of her invisibility within the perimeter" (148).
} 
enacts this democratic principle. ${ }^{42}$ While Sir Walter and Elizabeth dominate the opening chapters of the novel, they are judged by the reader not for their position, but their person, and are swiftly found to be lacking. Their erasure of Anne pre-empts their own narrative erasure. As Anne leaves Kellynch they are relegated to the background of the narrative and replaced by the more active, vital, and empathic naval figures, and only reintroduced at the novel's close to more forcibly emphasise their deficiency by comparison. Stuck in a past of their own making, Sir Walter and Elizabeth are in no way prepared to face the future and Anne must extricate herself from such a framework to avoid a similar fate. While Mr Woodhouse and Mr Tulliver are also remnants of an older time and often limited in their faculties, they have the affection and indulgence of reader and characters alike due to their warm-hearted natures. Sir Walter and Elizabeth may be pitied at the novel's conclusion but their selfishness and dismissal of Anne renders such a feeling fleeting. Instead they provide a decisive statement on their own ineptitude, especially in their inability to adapt to the new shifting and uncertain times. As Austen equates them "with the unhealthy ossification of the aristocracy at large, the desire to see them undermined comes to be associated with a broader desire for social change" (Nandrea 51-52).

Austen explicitly signals the landed gentry's necessary descent and loss of dominion through Sir Walter's coerced decampment from his ancestral home. The change of Kellynch Hall's residents can be read as enacting a larger social shift due to the country house's well established currency not only as "a metonym for the virtues of the landlord, but, as a political microcosm" standing in "for the state and ultimately for the nation" (Pohl 64). The Crofts, representative of the emerging and mobile professional classes, take over the helm from Sir Walter. Not only do they physically take his place-inhabiting the space he once inhabited and inheriting the duties and responsibilities which were once his - they far exceed him in their execution. Anne "felt the parish to be so sure of a good example, and the poor of the best attention and relief" (117). Where the Elliots left debt and disregard, the Crofts provide for those now under their care and humbly improve wherever they can. To render the Crofts indicative of their faction, rather than exceptional, Austen depicts the other naval officers, such as Captain Harville, as similarly magnanimous and utilitarian. Anne

\footnotetext{
${ }^{42}$ Joseph M. Duffy, for example, proposes that Persuasion is "heavily weighted on the side of the eager, liberal naval class against the fossilized aristocracy" (287).
} 
"could not but in conscience feel they were gone who deserved not to stay, and that Kellynch Hall had passed into better hands than its owners" (117).

The Crofts' influence is at once perceptive and practical — a marked departure from Kellynch Hall's original inhabitants. A number of pragmatic improvements have been made, such as the fixing of a troublesome laundry door and Admiral Croft's replacement of Sir Walter's profusion of large mirrors with his own small shaving glass (119). What was neglected is now repaired, and showy opulence and vanity have been replaced with the matter of fact utility required of a successful military man. ${ }^{43}$ Austen's own sparse style imbues the minute with an unusually intense power and her "worldly realism is nowhere more evident than in her awareness of 'things' as foci of identity formations, discursive ideological networks" and "residual and emergent social relations" (Morris 149). ${ }^{44}$ Thus, even the umbrellas at Kellynch Hall are part of Austen's wider social vision of transformation in Persuasion. The relocation of the household umbrellas from the butler's room where the Elliots kept them to hanging by the door where the Crofts prefer them enacts, in miniature, Anne's own physical journey (118). They progress from an increasingly redundant space dictated by class and tradition, to one eminently more logical and efficient. ${ }^{45}$ This transition is also one of practical democratisation and openness, as the umbrellas move from a restricted space to one where they are now accessible to anyone who passes through the door.

Anne's very dismissal and dehumanisation at the hands of her family endows her with the fluidity and mobility to shift from one social class to another. Whereas we meet Emma as a blooming young woman who has led a charmed life at Hartfield but must remain fixed there, Anne is a hollowed out version of herself who must be reanimated through relocation. She has no sense of belonging or affinity to a family member to impede her integration into a new social order and her very regeneration is

\footnotetext{
${ }^{43}$ An ideology of social change and improvement pervades the novel and can be seen in the Musgroves, who, "like their houses, were in a state of alteration, perhaps of improvement. The father and mother were in the old English style, and the young people in the new" (38). The Musgroves' ability to adapt and progress further highlights Sir Walter, Elizabeth and Mary's inability to do so.

${ }^{44}$ Similarly, "[t]he economy of narrative style is part of Persuasion's rebuke to ostentation and unnecessary extravagance" (Stafford 149-50).

${ }^{45}$ Posusta notes that at Louisa's fall Anne steps into action and "accepts that she can defy what had once been her place and choose the place which makes the most objective sense" (86).
} 
predicated upon her ability to distance herself from her past and instead embrace the unknown. Anne's "spirits improved by change of place and subject, by being removed" even "three miles from Kellynch" (44) Unshackled from the past and oppressive presence of her father and sister, Anne is free to gradually find her feet and voice - to relearn both herself and her attachment to Wentworth. Indeed, Wentworth's very presence begins to reawaken and reanimate Anne. And yet her time at Kellynch as an outsider in her own family, not only fostered a latent potential for decisive change, but also a keen observation and empathy that eases her transition into new environments. Lorri G. Nandrea posits that Anne's stagnation at Kellynch seems to allow "a greater sensitivity to the nuances of the present: a greater awareness of environments, of others, and of physical sensation" (Nandrea 54). Anne develops a porousness that renders her more responsive and open to her environment and those who comprise it. Thus, from the Lodge, to the Great House, Lyme, Kellynch with the Crofts, and Bath, Anne effectively enmeshes herself in the microcosm that surrounds her. She "acknowledged it to be very fitting, that every little social commonwealth should dictate its own matter of discourse; and hoped, ere long, to become a not unworthy member of the one she was transplanted into" (41). From arbitrating Mary and Charles's disagreements, to comforting the grieving Benwick, Anne is an active figure, making herself useful, and indeed invaluable, to those around her-a sharp contrast to her past dormant and dismissed self at Kellynch.

Through Anne's adaptation and integration into various households and environments, the novel enacts a shift from the aristocratic valuing of place and precedence to the meritocratic estimation of people's worth. While Austen reinforces the importance of family and locality, she cannot endorse those who are incapable or undesirous of seeing beyond it (Frey 217). In leaving Kellynch, Anne repeatedly proves her own value in her service to others, which culminates in her command and practical assistance after Louisa's fall. In consequence, she "had won" the Musgroves' enduring affection "by her usefulness when they were in distress" and is "claimed as part of the family" (207). Despite being connected to them through marriage, it is proving her worth and ability to serve their family that allows Anne to join their ranks. Like a naval officer, Anne is ready to contribute to a wider social concern rather than solely her own interests or those of her blood relations. It is this communal orientation that separates Anne from the declining aristocracy and instead 
facilitates her inclusion in a more open-ended and inclusive community. ${ }^{46} \mathrm{Her}$ meritocratic value system is also typified in her honouring an earlier engagement with her old school friend Mrs Smith instead of acting in the wishes of her father and sister to play the sycophant with their distant, yet titled relations (147-148). Austen demonstrates Anne's agency as she distances herself from her family and the values they embody. She breaches the role of dutiful and dependent daughter to instead become a more autonomous individual with the capacity to make her own moral judgements based on claims made on her other than blood ties. In regaining her own sense of self and what is due to her, Anne no longer as a matter of course gives her loyalty and dutifulness to her family to be taken for granted and ignored, but instead prefers giving it to one who has earned it through a genuine claim and earlier kindness.

The biggest threat to Anne's flourishing development is the possibility of a union with Mr Elliot - an event which would return her to Kellynch Hall, rejecting the possibility of her personal transformation and the novel's desire for social change on a larger scale. This option is made dangerously seductive for a moment not by the charms of the man himself, but by the rhetoric of Lady Russell, who has particular power in her place as a surrogate parent for Anne. ${ }^{47}$ Her reasoning is rendered all the more potent as it is predicated on the sense of love and home Anne had from her time with her mother: "The idea of becoming what her mother had been; of having the precious name of 'Lady Elliot' first revived in herself; of being restored to Kellynch, calling it her home again, her home for ever, was a charm which she could not immediately resist" (150). Lady Russell presents marriage to Mr Elliot as a complex metamorphosis of Lady Elliot's past into Anne's future (150). While futurity is emphasised, it is through a return to a life already lived and a past already enacted. The limitations of the projection are clear-Anne would be stepping into an outline of the previous Lady Elliot and be unable to go beyond-she could only be "superior" to her mother "in being more highly valued," not through any action or instinct of her

\footnotetext{
46 The openness and inclusivity of the naval officers is rather comically depicted and physicalised in the Harvilles' accommodation of the large party at Lyme- " they all went in-doors with their friends, and found rooms so small as none but those who invite from the heart could think capable of accommodating so many" (92).

${ }^{47}$ Claudia Johnson states that the very fact "Lady Russell stands not in place of mother, but rather "in the place of a parent" combined with "the very need to replace a living but morally dysfunctional father itself points to a problem with the conservative model" (155).
} 
own (150). Anne would be stepping backwards into a role which would calcify around her, refusing her the dynamism and possibility embodied by the navy and her own burgeoning mobility. Lady Russell's language is also unsettlingly monarchical. Anne would be "succeeding to all' her mother's "rights," "popularity" and "virtues" while "presiding and blessing" — an increasingly antiquated and backward image of patronage in view of the shifting political landscape and move towards greater equality (150). ${ }^{48}$ Anne's reanimation decisively begins after her departure from Kellynch and even this imagined return to "the same spot" produces a sense of artificiality and stagnation (150). Although she is temporarily "bewitched" by the prospect, she is soon brought back to herself by the idea of Mr Elliot himself and the knowledge she cannot reconcile herself to a future in which he is at the centre or which takes her back to where she began (150).

In eschewing the possibility of returning to her past and her practised obedience to her father and sister, and instead fashioning her own community, Anne enacts the policy of meritocracy and larger nationhood that guides the novel. Anne Frey explains that communities "founded on location prove insular and unable to connect even to proximate outsider, much less to feel the concerns of a social whole" (218). While still an important nexus, the family unit is no longer able to weather the turbulent and changing times alone. The novel tracks Anne's redressing of her loneliness and isolation at Kellynch by creating a more amorphous family out of a collection of groups and individuals who provide her with the warmth, affection and sense of belonging that she previously lacked. In doing so, she creates a network of forged and bound through a continuous exchange of mutual affection and duty that has been earned, not assumed as a right. Consequently, this expanded, and fluid network is one more able to reconcile the difficulties of the individual and the collective, as is illustrated in Wentworth's recovery of Mrs Smith's husband's property in the West Indies when she previously had no one to act for her (235).

In her union with Wentworth, Anne regrets "the consciousness of having no relations to bestow on him which a man of sense could value” (235). While Sir Walter and Elizabeth derive their importance and identity from the 'Elliot pride,' the novel has made abundantly clear that their 'worth' is minimal. However, in Lady Russell, Mrs Smith and the multitude of Musgroves, Anne has a loving community ready to

\footnotetext{
${ }^{48}$ Possibly a nod to Sir Walter's clear monarchical bent in naming his daughters Elizabeth, Anne and Mary as opposed to Louisa, Henrietta or Penelope for instance.
} 
amalgamate both Wentworth and the naval society he is part and parcel of. Place is no longer a geographic location or inherited establishment but a collection of 'worthy' people, exemplified by the hero's name, which Anne herself will soon share. ${ }^{49}$ Thus, while Anne and Wentworth may not have a specified physical home, they have created a web of relationships in which they are sheltered and supported.

The opening out of the narrative's end makes clear that such support could indeed be necessary. In one sense the novel is a return - a revisiting of Anne and Wentworth's initial momentary blissful union - but it is not a reliving of it since both have progressed beyond their past selves. Their relationship has evolved along with them and been enriched by their later experiences and growth. Fundamentally, the ending refuses complete closure through its thrusting of the couple, not back, but forward. Austen tempers the sweetness of happy ever after with a note of bitterness in the reality that Anne must pay for her happiness in the form of a "tax of quick alarm" inherent in her new position as a navy wife (236). Given the explicit historic moment, later readers know that Anne's 'tax' will soon have to be paid in the announcement of Napoleon's escape. As the final sentence moves from the past tense to the present, it also shifts the novel from "fiction to history" as the narrative action is poised on the brink of the historic present (Nandrea 59).

Anne and Wentworth are transported to an unknowable future and the cost of the dynamism and freedom of this prospect is necessarily the uncertainty of it. However, Austen illustrates that the unpredictability of this future is far preferable than returning to the circular stagnation that typified by life at Kellynch. Like Emma's relationship with Knightley, in Persuasion Austen also provides a partial reflection of life beyond the final page. While Anne has never encountered anything as extreme as possible war, the novel has seen her integrate and adapt into a variety of new situations, and this new found flexibility and sense of self combine to reassure the reader of her now well-practiced ability to face the unknown head on, especially with Wentworth at her side. In Anne's choice of Wentworth, not Mr Elliot, she chooses not only love and her compatible partner-but also the future not the past - a man committed not to himself, but his community and country, and a life together that

\footnotetext{
${ }^{49}$ This sentiment has already been embodied in the text by Mrs Croft who comfortably spent many years at sea and claims her happiness is reliant not on her physical surroundings, only the proximity of the Admiral: "While we were together, you know, there was nothing to be feared" (66).
} 
embraces the dynamic uncertainty and progress of the navy as opposed to returning to the increasingly redundant and decaying aristocracy. Anne chooses the tempestuousness, vastness, and possibility of the sea over Kellynch Hall.

\section{Middlemarch-the "new real future" (182)}

At the heart of George Eliot's magnum opus Middlemarch stands a heroine without a father and without a childhood - a heroine, indeed, without a past. While Dorothea and Maggie markedly resemble each other in several shared traits-their intense ardour, a desire to be learned, striking eyes and a penchant for looking best in plain dress-Eliot places her two heroines in diametrically opposed positions. Maggie is inherently bound, not only to her father and family, but also to the very site of her origin. Her experience is one of cyclical return and violent grappling with her past before she finally becomes subsumed into it by the flood. Dorothea's grappling is necessarily of a different nature, as at the novel's start she has her sister and uncle, but there is no sense that she is bound to them by substantial ties of duty, love, or devotion, as Maggie is with her family. When this absence is combined with the fact Dorothea has only been living at Tipton with her uncle for "hardly a year" it becomes apparent that she begins the novel with no sense of home to negotiate, contend with, define or sustain her (8). I suggest that Dorothea's marriage to Casaubon and her resulting temporary ossification has obscured to readers the sheer mobility and fluidity of her character. Whereas Austen imbues Anne with dynamic mobility and possibility through rendering her past distinctly undesirable to return to in the form of her father and sister, Eliot achieves the same end through the complete erasure of Dorothea's personal history. Dorothea has no childhood but is defined by her 'childlikeness,' and it is this paradox that renders her mouldable, mobile, and open to new beginnings.

In removing Dorothea's past, Eliot imbues her with a sense of charged potential and formlessness, rendering her uniquely suited to adapt to the moment of historical transformation. Middlemarch is set between 1829-1832 during the turbulent passing of the First Reform Bill, 40 years prior to when Eliot was writing, and the Second Reform Bill was dominating English politics. The novel is consequently pervaded with a "sense of impending social change of uncertain magnitude" and "reform not just in the political sense but in a more extended sense that included scientific, political, religious, and personal change" (Chase, Middlemarch 3). By 
locating her narrative in a rural Midlands town, Eliot presents not the epicentre of change, but a community on the outskirts reluctantly teetering on the brink of transformation. Dorothea's lack of significant ties to places and people in her past allows her to embody the wider-scale change which her community must necessarily undergo. She embraces uncertainty and decisive transition through integrating herself into the enterprising urbanisation and more progressive social structure of London at the novel's close.

Dorothea's absent childhood is not only a striking anomaly in regard to Maggie and the other protagonists discussed in this thesis, but also in light of the significance Middlemarch elsewhere places on childhood. Many critics conflate Woolf"s famous declaration that Middlemarch is "one of the few English novels written for grown-up people," with the judgement that the novel itself is only concerned with the state of adulthood (213). Alan Mintz typifies this position in his claim that "Middlemarch is a consummately adult world in which the experiences of childhood and youth barely figure" (57). However, Eliot's intense interest, so evident in Mill, in childhood and its bearing on the individual's development has not simply disappeared but is once more central to Middlemarch. The novel's pages abound with children. The young Vincy and Garth children come to mind first, but there are also those played with by Lydgate, snuck sugar by Miss Noble, and of course born to Celia, Mary, Rosamond and Dorothea in the novel's finale. Moreover, 'child' is not simply an initial phase of development to be shaken off with age but a role that continues indefinitely. At its most foundational level, the novel's web of relationships is comprised of those of parent, child, and sibling, and the question of what it means to adequately fill those roles is figured repeatedly among the main characters, particularly the Vincys and Garths. Fundamentally, the novel is concerned with the development both of a series of individuals and the community as a whole. Thus, one of Middlemarch's primary considerations is to show the gossamer threads between past, present and future - how "what we have been makes us what we are" (660). Childhood is consequently a crucial aspect of the novel's machinery. The critical difference between Mill and Middlemarch's depiction of childhood then, is not the importance they place on it, but the manner in which childhood is so definitive for one protagonist and so completely absent for the other.

Instead of possessing a realised childhood in the novel, Dorothea is instead provided with a surrogate one in St Theresa's, through which her own 'child-like' 
nature is manifested. While Dorothea is likened to a range of historical and mythical figures, St Theresa provides the dominant parallel and this is signalled in the novel's prelude not being a personal history of Dorothea, but instead a childhood episode from the life of the Spanish nun who lived 300 years prior. The young Saint Theresa "walking forth one morning hand-in-hand with her still smaller brother, to go and seek martyrdom in the country of the Moors" initially seems a more fitting preface to Mill rather than Middlemarch, echoing as it does the idealised image of Maggie and Tom roaming the daisied fields together (3). Through placing it at the start of Middlemarch, Eliot foregrounds the significance of childhood in the work, even as she simultaneously eschews it in Dorothea. The narrative's invocation of St Theresa has been frequently read as acting to primarily emphasise the limitations and restrictions Dorothea's environment place upon her and the consequent disparity between her domestic life and St Theresa's "epic" one (3). ${ }^{50}$ While this reading emphasises Dorothea's struggle to find a fulfilling calling, it downplays the extent to which St. Theresa's childhood excursion stands symbolically in for Dorothea's empty childhood and reflects her fundamental character. ${ }^{51}$ Like Theresa, Dorothea has a "passionate, ideal nature" (3) and throughout the novel is frequently referred to as "childlike", "childish" and simply called "child" (10, 34, 193). Dorothea's 'childishness' means she can be naïve and misguided, but also optimistic, kindhearted and adaptable. The narrative's endorsement of her manner can be seen in the way she does not 'outgrow' her child-like quality, as the Bildungsroman would dictate, but instead maintains it throughout the narrative while also gaining a more nuanced understanding of the world around her. This developed dual nature proves that St. Theresa's "child-pilgrimage was a fit beginning," not only for her own life, but also Dorothea's (3).

The vacuum of Dorothea's family and past is acutely apparent in the scene in which it should be the most prominent — when Dorothea and Celia try on their dead mother's jewels (11-14). The only mention of her parents collectively is the narrator's almost absentminded mention of their death when the girls were "about twelve years

\footnotetext{
${ }^{50}$ Sherry Mitchell's view is a common one, that "where Teresa ... had been allowed to write and initiate reforms among the Carmelites, Dorothea is presented as being hopelessly contained by a combination of Victorian social practices and discourses of normative femininity" (33).

${ }^{51}$ For more on sustained works on St Theresa's significance in the novel see Sherry Mitchell and Hilary Fraser's articles.
} 
old" (8). No further explanation or detail is provided. It is only in this initial exchange over her jewels that their mother is glimpsed but this is done in a manner than only highlights her erasure. Despite her initial disinterest and planned renunciation of the jewels, Dorothea is captivated by an emerald ring and bracelet. She attempts to transfigure her delight in their beauty into religious ardour by calling them "fragments of heaven"; however, this process is interrupted by her acknowledgment of their corporality and the "miserable men" associated with their discovery and production (13). Dorothea exemplifies her fragmented nature as she tries to reconcile her aesthetic joy, religious fervour and acknowledgment of the material world around her, but ultimately is left only with an uneasy acceptance of the jewels that does not satisfy her ethos of unworldly selflessness or worldly pragmatism. The resulting "unstable compromise indicates the disorganization of desire produced by Dorothea's simultaneous engagement with multiple ideas of value" (Freegood 128). ${ }^{52}$

Eliot utilises the scene with the late Mrs Brooke's jewels to illustrate how both Dorothea and the jewels operate separate to the past and its determining influence. What is striking is the manner in which the jewels' principal function of worth - their sentimental value as remnants of a presumably beloved dead mother-is completely absent and ignored. Before Dorothea sees the jewels, she cries off them with the almost flippant response that she has "other things of mamma's - her sandal-wood box which I am so fond of-plenty of things" (12). However, when she truly desires them, she is assaulted by their multiple potential meanings except the one that most naturally justifies her possession of them. This omission is all the more glaring given the Victorian cult of the dead and the profusion and significance of mourning jewellery and paraphernalia at the time. As Judith Pascoe notes, it was a "time when the notion that objects are imbued with a lasting sediment of their owners" prevailed (3). Contrary to this, the emeralds are emptied of any sense of sentiment, inheritance, past possession, or memory - emptied of any remnant of the late Mrs Brooke. They exist only as objects in their own right. Dorothea's refusal of this emotional connection initially seems unsettlingly callous and detached. Nina Auerbach expresses her disapprobation at Dorothea's "spurning" of the "treasure of fellowship"

\footnotetext{
52 Joseph Wiesenfarth views Dorothea's interaction with the emeralds as illustrating how her "[m]oral commitment tempers a response to aesthetic objects with an awareness of social responsibility" (364). See also Katherine Dunagan Osborne's argument on the Eliot's subversion of the jewels from symbols of inheritance to vehicles of "fluid interiority" and female subversion (467).
} 
as "[f]amily jewels are a clasp from the past" (88). However, I suggest the scene acts to illustrate how Dorothea cannot reject familial fellowship, as she does not have a past or family to reject. This formulation of familial absence is reinforced by the narrative's complete avoidance of any further reference to her parents and complete omission of any emotional language surrounding them or their death. Unlike Anne Elliot's, Dorothea's mother does not truly exist in her memory, mental landscape, or the narrative itself. ${ }^{53}$ The emeralds are thus hollowed out of any familial identity, just as Dorothea is, and both are consequently free to generate their own meaning and operate on their own worth without genetic inheritance or status as a another's possession to dictate their character or value.

Dorothea's ability to choose to marry Casaubon reveals the freedom of her position untied to any deference to familial opinion. Unlike Maggie, Dorothea is not impacted in her interaction with potential suitors by her family's resentment and grievances. The very fact that Dorothea can marry Casaubon, against the wishes of those around her, demonstrates the liberty and potential dangers, of her untethered position. Whereas Anne is dissuaded from marrying Wentworth through her family's disapproval and Lady Russell's reasoning, Dorothea cannot be similarly influenced. While she loves her uncle and sister, her affection for them has no significant weight in her cognitive process, and they do not alter her decisions or actions, again hollowing out the dominance of family authority. The young St Theresa is turned back from her childhood pilgrimage when "domestic reality" met her "in the shape of uncles" (3). Conversely, Mr Brooke, who similarly holds the position of Dorothea's guardian, repeatedly demonstrates his inability to exert paternal control over her or in any way regulate her behaviour. The most significant ramification of this is that Dorothea has the freedom to accept two suitors who are almost universally regarded as unsuitable. Given the ineffectuality of Mr Brooke to guide or impose his authority, before marriage Dorothea is in the unique position of being able to act essentially as she wishes, subject only to the demands of her own desires and principles.

\footnotetext{
${ }^{53}$ It is interesting to note that Anne and Dorothea are only two years different in age when their mothers pass away. Anne "had gone unhappy to school, grieving for the loss of a mother whom she had dearly loved, feeling her separation from home, and suffering as a girl of fourteen of strong sensibility and not high spirits, must suffer at the time" (143), whereas Dorothea and Celia "were about twelve years old and had lost their parents"-with no mention of any consequent grief or mourning (8).
} 
Dorothea's lack of past endows her with freedom but also a sense of oppressive indefiniteness and aimlessness that leads her to seek definition in marriage with Casaubon. Unable to truly devote herself to a cause at Tipton, the prospect of marital devotion to Casaubon comes with the intensity of a spiritual epiphany that echoes Maggie's discovery of Thomas á Kempis - it was “as if a winged messenger had suddenly stood beside her path and held out his hand towards her!" (26). Her future once vague and uncertain now gains a solid definition. Her desire is explicitly for a husband who "was a sort of father" - a Milton or Hooker figure to guide and instruct her (10). However, after marriage, the reality of her and Casaubon's inherent separateness gradually impresses itself upon her consciousness (399-400). The "access to knowledge Dorothea had thought would free her instead entraps her" (Livingston 95). On her honeymoon to Rome, Ladislaw and Naumann find Dorothea near a statue of Ariadne/Cleopatra and the antithesis is made explicit between "reclining marble" and "a breathing blooming girl" (177). This moment marks the beginning of Dorothea's temporary transformation into a similarly transfixed state. Back at Lowick, she "shut her best soul in prison, paying it only hidden visits" to accommodate herself to fit her husband's character and expectations (400). This symbolic calcification reaches its climax just as she is about to break free of it. At the news of Casaubon's codicil about Will, Dorothea initially flushes and then "turned cold again" (460). Her hand when touched is "of a marble coldness" (461). Whereas Anne begins the novel in a state of stagnancy and dilapidated physicality, Dorothea remains blooming, even during her very similar state of internal restriction and petrification-even her mourning apparel only serves to highlight her bright appearance (505). Her radiant physicality belies the physiological hardship and isolation she has endured and prefaces her reanimation as her childlike nature and resilience are revitalised.

Dorothea's transition from Casaubon to Will Ladislaw is explicitly demarcated as a shift from past to future. Casaubon is a figure firmly entrenched in archaic history and mythology, and his laborious research method is, like the mill in Eliot's earlier novel, defined by movement without progress. Both his composition and own person are depicted as being increasingly redundant and unable to adapt to their changing environment. The half-formed "Key to all Mythologies" fails to account for other philosophical thought and is consequently deficient "for want of knowing what is being done by the rest of the world" (194). Echoing his work, the 
man himself is frequently likened to an organism ill adapted to survival, change, and the environment it finds itself in. He becomes an unsettling figure of pathos and pity in the narrator's descriptions of his limitations. His soul "went on fluttering in the swampy ground where it was hatched, thinking of its wings and never flying," and after a particularly upsetting argument Dorothea resists responding aggressively and feels as if she "had narrowly escaped hurting a lamed creature" $(262,401)$. Beer conflates the failures of his work and relationships, noting that, "Casaubon cannot accept the protean nature of myth because renewal and embodiment are beyond his imaginative grasp. Dorothea may be a poem to Ladislaw; she is never, in any sense, myth to Casaubon" (George Eliot 163). ${ }^{54}$ Casaubon not only isolates himself, but also keeps Dorothea cloistered away with him, hindering her from fulfilling her desire to contribute meaningfully to her community. Casaubon cannot accept, adapt or contribute to the protean environment shifting around him, rendering both himself and his work remnants of the past which have no place in an evolving future.

At the opposite end of the spectrum to Casaubon's solid inadaptability is Will Ladislaw, who is a figure of almost excessive fluidity. Will's quixotic family past and roaming nature threaten the established Middlemarch landed gentry. He cannot be put in his place as no one is quite sure where indeed that is. Even his physicality refuses to be clearly delineated-"Surely, his very features changed their form, his jaw looked sometimes large and sometimes small; and the little ripple in his nose was a preparation for metamorphosis" (196). ${ }^{55}$ Will is consistently associated with imagery of regeneration and growth, such as the sun and spring, which are often implicitly contrasted to the faded and wasting Casaubon. Mrs Cadwallader mockingly calls him “a very pretty sprig", acknowledging both his attractiveness and his latent potential to bloom (309). Will's formlessness and indeterminacy are crucial in allowing Dorothea the space to grow in his presence. When she first hears him acknowledge his love for

\footnotetext{
${ }^{54}$ Sally Livingston also notes that Casaubon's “intellectual interests situate him in the past: he is an old-fashioned scholar, just as his marriage with Dorothea is oldfashioned" (95)

${ }^{55}$ Will's features resemble those of his Aunt Julia, who is a narrative forebear to Dorothea in her abandonment of her family and status for the man she loves and a life of precarious indeterminacy (73). Notably, Dorothea sentimentally treasures Aunt Julia's miniature as opposed to the lack of emotional connection she feels concerning her mother's jewels. Aunt Julia has a stronger hold over Dorothea given both her resemblance to Will and her similar act of social transition and transgression through her marriage.
} 
her, "It was as if some hard icy pressure had melted, and her consciousness had room to expand: her past was coming back to her with larger interpretation" (596). The 'hard icy pressure' linked to her ossification and claustrophobic existence with Casaubon is melted in the warmth and spaciousness of Will's presence.

Will crucially allows Dorothea to return to her impetuous and childlike state that so unsettled Casaubon. Will himself is a pied piper figure, who "had somehow picked up a troop of droll children" in Middlemarch and is consequently able to enmesh himself in a community rather than stand outside it (435). Eliot often describes Dorothea and Will in childlike terms. When they confess their love for each other they stand "with their hands clasped, like two children, looking out on the storm" (761). ${ }^{56}$ Their union is thus charged with a sense of possibility and beginning, if also with naïve idealism. While Will has been frequently criticised for being an unrealised character and unworthy of Dorothea, reminiscent of Stephen's inadequacy for Maggie, his suitability lies in his very indefiniteness and childlike nature, which regenerates and heightens these traits in her. ${ }^{57}$ Her regained formlessness and childlikeness generates the "incalculably diffusive" effect on those around her and allow her to adapt to the new, urban environment of London (785). In marrying Will, Dorothea rejects her land, status and wealth. She leaves behind the placid rural landed gentry for the vitality and possibility of the bustling metropolis.

As in Persuasion, Dorothea's union with Will enacts a new meritocratic ideology that judges value based on utility and benefit to the wider community, rather than insular concerns and status. Anne and Dorothea both eschew their own social position for an uncertain future with men "whose only capital was in their brains" (273).$^{58}$ Just as Wentworth serves his country in the navy, Will "became an ardent public man, working well in those times when reforms were begun with a young hopefulness" (782). For Austen and Eliot, the Mr Elliots and Mr Casaubons in their self-interest or insular projects are no longer fitting partners for their heroines. Like the child St Theresa and her brother, they must have "human hearts . . . beating to a

\footnotetext{
${ }^{56}$ Earlier "They were looking at each other like two fond children who were talking confidentially of birds" (368).

${ }^{57}$ For instance, F. R. Leavis is highly critical of Will- "He is not substantially (everyone agrees) 'there"” and he compares him, unflatteringly, to "Lydgate, who, unlike Ladisalw, is real and a man" (93-94).

${ }^{58}$ Although, Wentworth now also can provide Anne with the fortune he made at sea (29).
} 
national idea" (3). Commitment solely to the individual and the nuclear family is no longer sufficient, instead service must be made to a wider and more disparate community for the progression of society as a whole. In keeping with this shift, stability and security must also be exchanged for uncertainty and possibility.

Critics have frequently been disappointed with what they see as Dorothea's regression and relegation at the novel's close to a mother and wife instead of achieving the prospect of a grander future. However, in the novel's end, Eliot deliberately frustrates a sense of simple closure and undercuts the efficacy of such 'grandeur'. Dorothea is commonly referred to as 'queenly' throughout the novel. When Celia hears of Dorothea's planned marriage to Will, she observes, "James always said you ought to be a queen; but this is not at all being like a queen," and her thought echoes the disappointed reader's that Dorothea has descended from her elevated position (771). Eliot critiques this standpoint in her satirical outline of a typical novel in her essay "Silly Novels by Lady Novelists" (1856). She notes that the heroine frequently "wears some family jewels or other as a sort of crown of righteousness at the end" (75). Having already eschewed her own family jewels, Dorothea also symbolically refuses a "crown of righteousness" as she renounces her wealth and social status as a rich noblewoman to instead become a London wife and mother. This change is more in keeping with her character, as she never felt "at ease in the perspective and chilliness of [the] height" of her prior position (306) ${ }^{59}$ Like the image of Anne 'reigning' as her mother at Kellynch Hall, the idea of Dorothea remaining unmarried at Lowick like those around her wish, reveals the emptiness of such images of dignity and the dangerous stagnation and regression implicit in their enaction. These proposed elevated positions oppose the democratising impulse at the heart of both novels.

Dorothea does not progress from her idealism and naivety to a cold and distant maturity but retains her childlike vigour and resilience with a new awareness of the complexity of relationships and her environment. For "Dorothea, then, to age is to

\footnotetext{
${ }^{59}$ Eliot is dubious about the superiority and complacency inherent in being 'queenly', such as Maggie allowing her hair to be plaited into a crown. Dorothea's renunciation of her 'reigning' status at the novel's end is echoed also by Romola in the epilogue who has been forced into such a transition- "life had left its marks upon her: the finely-moulded cheek had sunk a little; and the golden crown was less massive; but there was a placidity in Romola's face which had never belonged to it in youth" (581). Queenliness in Eliot is inherently replaced by a quieter awareness of a more prosaic life.
} 
emerge more childlike than she was at the start" (Chase, "Introduction" 9). Dorothea's childhood was already hollowed out but she also actively rejects a wider sense of the past in her renunciation of her landed and monarch-like position. She instead embraces the future by becoming part of the masses in a city at the centre of dynamic social change and progression. The likening of Dorothea's "full nature" to "that river of which Cyrus broke the strength," at the novel's conclusion echoes Maggie's unification with the flooded Floss. However, where Maggie had no socially sanctioned outlet, Dorothea's ardour can be channelled in her new position in London, even if it is through "channels which had no great name on earth" (785). Echoing Austen's move at the end of Persuasion, Eliot also opens the conclusion of Middlemarch out to the present. The narrator includes the reader in their approbation of small rather than historic acts: "that things are not so ill with you and me as they might have been, is half owing to the number who lived faithfully a hidden life" (785). In her new domestic, prosaic and half-hidden role, Dorothea and her childlike ardour can influence those around her in a more meaningful way, Eliot suggests, than either queen or saint. 


\section{Conclusion}

"To want to be a heroine is to want to be something special, something else, to want to change, to be changed, and also to want to stay the same" - Rachel M. Brownstein, 'Becoming a Heroine' (xv)

In recent years, female experience, both real and fictional, has taken an increasingly prominent place in public, literary and political discourse. Building on the seminal feminist texts of the 1970s onwards, current scholarship has been doing crucial work in interrogating the depiction of womanhood and the power dynamics that surround it, both in the established, often male, canon and in the creation of an alternative, more inclusive literary tradition. This effort is both necessary and enlightening in presenting new modes of viewing female authored and centric texts; however, like the scholarship of the female Bildungsroman, at times it understandably tends toward a cynical language of female oppression and retrogression. Consequently, one of the central aims of this thesis has been to take foundational texts from two of the most influential nineteenth-century authors and provide a reading attuned to their depiction of female progression, prosperity and connectivity.

Margaret Fuller wrote in 1833-poised at midpoint between Austen and Eliot's novels - "I am suffocated and lost when I have not the bright feeling of progression" (216). While Persuasion is unambiguously a narrative of female progression, Emma, The Mill on the Floss, and Middlemarch have been frequently classified as depicting female regression, compromise and restriction. This thesis argues for a reclamation and reclassification of these texts as ones of female development and success, with the understanding that both authors were working within the conventions of their time and form. Austen, and particularly Eliot, are certainly alert to the necessity of change in their works and they prosaically and pragmatically depict moments when the heroine is "suffocated and lost," disillusioned and disappointed (216). Part of the heroine's development is to obtain a more nuanced understanding of the reality and often harshness of the world they operate in. Dorothea's position is indicative of all the heroines in that they must reconcile themselves to "the new real future which was replacing the imaginary" (182). However, this merging of projected future and present is simply part of their 
maturation and each novel culminates in an act of female triumph. Emma engineers her position at Hartfield to include her roles of both daughter and wife and is therefore spared the severing of her past identity for a separate future one. In a whirlwind of female movement and agency, Maggie ends the novel united with the Floss - her true home - and in doing so refuses to conform to a restrictive feminine ideal. And Anne and Dorothea both leave behind the stagnancy and stillness of their old lives as part of the rural aristocracy to instead become part of a more dynamic community and meritocratic social order. Whether it is by remaining at home or travelling elsewhere-Austen and Eliot depict their heroines formulating futures on their own terms.

Through paralleling their heroines' development with their societies' transformation, Austen and Eliot place the female's experience of growth and marriage at the heart of societal transition and progress. The shifting scale in Austen and Eliot's oeuvres is evident in the concluding words of each novel. We move from "the small band of true friends" in Emma (453), to Anne's "belonging to that profession which is, if possible more distinguished in its domestic virtues than in its national importance" (236). Similarly, Eliot progresses from the union of Maggie with Tom, her father, the Floss - "In their death they were not divided" (518) - to Dorothea whose nature "spent itself in channels which had no great name on the earth" but accumulates "for the growing good of the world" (785). Austen and Eliot consequently end their later novels with a more national and global vision of influence, while placing the heroine at the centre of such change. 


\section{Works Cited}

Ablow, Rachel. The Marriage of Minds: Reading Sympathy in the Victorian Marriage Plot. Stanford UP, 2007.

Amiel Houser, Tammy. "The Ugly Duckling' and The Mill on the Floss: A FairyTale Rewriting of the Bildungsroman.” Women's Studies, vol. 45, no. 6, 2016, pp. 549-569.

Anonymous. Review of The Mill on the Floss. Spectator, 7 April 1860. Repr in The Mill on the Floss, edited by Oliver Lovesey, Broadview, 2007, pp. 547-551.

Armstrong, Nancy. Desire and Domestic Fiction; A Political History of the Novel. Oxford UP, 1987.

---. "The Gothic in Austen.” A Companion to Jane Austen, edited by Claudia L. Johnson and Clara Tuite, John Wiley and Sons, 2009, pp. 237-247.

Auerbach, Emily. Searching for Jane Austen. University of Wisconsin Press, 2004.

Auerbach, Nina. "Dorothea's Lost Dog." Middlemarch in the Twenty-First Century, edited by Karen Chase, Oxford UP, 2006, pp. 87-105.

---. "The Power of Hunger." Nineteenth-Century Fiction, vol. 30, no. 2 , 1975, pp. 150-171.

Austen, Jane. Emma. Edited by Fiona Stafford, Penguin, 2015.

---. Jane Austen's Letters. Edited by Deirdre Le Faye, Oxford UP, 2011.

---. Mansfield Park. Edited by June Sturrock, Broadview, 2001.

---. “Opinions of Emma: collected and transcribed by Jane Austen.” Reprinted in Jane Austen: The Critical Heritage; Volume 1 1811-1870, edited by B. C. Southam, Taylor and Francis, 1995.

---. Persuasion. Edited by Gillian Beer, Penguin, 2015.

---. Pride and Prejudice. Edited by Vivien Jones, Penguin, 2014.

Bardi, Abby. "'Gypsies' and Property in British Literature: Orlando and Wuthering Heights." "Gypsies" in European Literature and Culture: Studies in European Culture and History, edited by Valentina Glajar and Domnica Radulescu, Springer, 2008, pp.105-124.

Beer, Gillian. George Eliot. Indiana UP, 1986.

---. “Introduction.” Persuasion. Edited by Gillian Beer, Penguin, 2015. 
Berendsen, Margaret. Reading Character in Jane Austen's Emma. Van Gorcum, 1991.

Bevir, Mark. "Historicism and the Human Sciences in Victorian Britain." Historicism and the Human Sciences in Victorian Britain, edited by Mark Bevir, Cambridge UP, 2017, pp. 1-20.

The Bible. Authorized King James Version, Oxford UP, 2008.

Birtwistle, Sue, and Susie Conklin. The Making of Jane Austen's Emma. Penguin, 1996.

Blind, Mathilde. George Eliot. Eminent Women Series. W. H. Allen, 1883.

Bodenheimer, Rosemarie. The Real Life of Mary Ann Evans: George Eliot, Her Letters and Fiction. Cornell UP, 1994.

Booth, Wayne C. The Company We Keep: An Ethics of Fiction. U of California P, 1988.

Bradley, A. C. "Jane Austen.” Lecture given to the English Association at Newnham College, Cambridge, 1911. Reprinted in Jane Austen: The Critical Heritage; Volume 2 1870-1940, edited by B. C. Southam, Taylor and Francis, 1995.

Bree, Linda. "Emma: Word Games and Secret Histories.” A Companion to Jane Austen, edited by Claudia L. Johnson and Clara Tuite, John Wiley and Sons, 2009, pp. 133-142.

Brontë, Charlotte. Jane Eyre. Edited by Stevie Davies. Penguin, 2006.

Brontë, Emily. Wuthering Heights. Edited by Pauline Nestor, 2003.

Brownstein, Rachel. Becoming a Heroine: Reading about Women in Novels. Columbia UP, 1994.

---. Why Jane Austen? Columbia UP, 2011.

Buckley, Jerome. Seasons of Youth; the Bildungsroman from Dickens to Golding. Harvard University Press, 1974.

Calder, Jenni. Women and Marriage in Victorian Fiction. Oxford UP, 1976.

Chase, Karen. Eliot: Middlemarch. Cambridge UP, 1991.

---. "Introduction." Middlemarch in the Twenty-First Century, edited by Karen Chase, Oxford UP, 2006, pp. 3-14.

Cohen, Paula Marantz. The Daughter's Dilemma: Family Process and the Nineteenth-Century Novel. U of Michigan P, 1993.

Dever, Carolyn. Death and the Mother from Dickens to Freud: Victorian Fiction and the Anxiety of Origins. Cambridge UP, 1998. 
Duckworth, Alistair M. The Improvement of the Estate; a Study of Jane Austen's Novels. Johns Hopkins Press, 1971.

Duffy, Joseph M., Jr. “Structure and Idea in Jane Austen's Persuasion.” NineteenthCentury Fiction, vol. 8, no. 4, 1954, pp. 272-89.

DuPlessis, Rachel. "Endings and Contradictions." Narrative Dynamics: Essays on Time, Plot, Closure, and Frames, edited by Brian Richardson, James Phalen and Peter Rabinowitz, Ohio UP, 2002. 282-299.

---. "For the Etruscans." The New Feminist Criticism: Essays on Women, Literature, and Theory. Edited by Elaine Showalter. Pantheon Books, 1985.

Duncan, Ian. "Literature.” Historicism and the Human Sciences in Victorian Britain, edited by Mark Bevir, Cambridge UP, 2017, pp. 105-127.

Eliot, George. George Eliot's Life, as Related in Her Letters and Journals, vol. 1. Edited by John Walter Cross, Cambridge UP, 2010.

---. Middlemarch. Edited by David Carroll. Oxford UP, 2008.

---. The Mill on the Floss. Edited by Oliver Lovesey, Broadview, 2007.

---. Romola. Edited by Dorothea Barrett, Penguin, 1996.

---. The Lifted Veil and 'Silly Novels by Lady Novelists.' Penguin, 2016.

Eliot, T. S. "Burnt Norton” Four Quartets. Houghton Mifflin Harcourt, 2014, pp. 13.

Ellis, Lorna. Appearing to Diminish; Female Development and the British Bildungsroman, 1750-1850. Bucknell University Press, 1999.

England, Catherine. "Slipping into Marriage: How Heroines Create Desire by Risking Their Reputations.” Victorian Review, vol. 40, no. 2, 2014, pp. 109-124.

Esty, Joshua. "Arresting Development in The Mill on the Floss." Narrative, vol. 4, no. 2, 1996, pp. 142-160.

Fraser, Hilary. "St. Theresa, St. Dorothea, and Miss Brooke in Middlemarch." Nineteenth Century Fiction, vol, 40, no. 4, 1986, pp. 400-411.

Freegood, Elaine. The Ideas in Things: Fugitive Meaning in the Victorian Novel. Chicago UP, 2006.

Friedman, Susan Stanford. Planetary Modernisms. Columbia UP, 2015.

Frey, Anne. "A Nation Without Nationalism: The Reorganization of Feeling in Austen's Persuasion.” NOVEL: A Forum on Fiction, vol. 38, no. 2/3, 2005, pp. 214-234.

Fuller, Margaret. The Letters of Margaret Fuller. Edited by Robert N. Hudspeth, 
Cornell UP, 2018.

Galperin, William H. The Historical Austen. U of Pennsylvania P, 2013.

Gay, Penny. "Emma and Persuasion." The Cambridge Companion to Jane

Austen, edited by Edward Copeland and Juliet McMaster, Cambridge UP, 2010, pp. 55-71.

Gilbert, Sandra M., and Susan Gubar. The Madwoman in the Attic; the Woman Writer and the Nineteenth Century Literary Imagination. Yale UP, 1979.

Golban, Petru. A History of the Bildungsroman: From Ancient Beginnings to Romanticism. Cambridge Scholars Publishing, 2018.

Gonda, Caroline. Reading Daughter's Fictions 1709-1834; Novels and Society from Manley to Edgeworth. Cambridge UP, 1996.

Greiner, Donald J. Women Without Men: Female Bonding and the American Novel of the 1980s. U of South Carolina P, 1993.

Griest, Guinevere L. Mudie's Circulating Library and the Victorian Novel. Indiana UP, 1970.

Guth, Deborah. George Eliot and Schiller: Intertextuality and Cross-Cultural Discourse. Routledge, 2016.

Harvey, W. J. The Art of George Eliot. Chatto and Windus, 1963.

Hecimovich, Gregg A. Austen's Emma. Continuum, 2008.

Hensley, Nathan K. "Database and the Future Anterior: Reading The Mill on the Floss Backwards." Genre, vol. 50, no. 1, 2017, pp. 117-137.

Henson, Eithne. Landscape and Gender in the Novels of Charlotte Brontë, George Eliot, and Thomas Hardy; The Body of Nature. Ashgate, 2013.

Homans, Margaret. Bearing the Word: Language and Female Experience in Nineteenth Century Women's Writing. Chicago UP, 1986.

Jager, Colin. "Wishing for Nothing; Emma and the Dissolution." Unquiet Things; Secularism in the Romantic Age. U of Pennsylvania P, 2015.

James, Henry. "The Novels of George Eliot." Views and Reviews, edited by Le Roy Phillips, The Floating Press, 2017.

James, William. The Principles of Psychology. Volume 2. H. Holt, 1890.

Jenkyns, Richard. A Fine Brush on Ivory; An Appreciation of Jane Austen. Oxford UP, 2004.

Johnson, Claudia L. Jane Austen; Women, Politics, and the Novel. University 
of Chicago Press, 1988.

Jones, Ann Rosalind. "Inscribing Femininity: French Theories of the Feminine." Making a Difference: Feminist Literary Criticism, edited by Gayle Greene and Coppelia Kahn, Routledge, 1985.

Kermode, Frank. The Sense of an Ending: Studies in the Theory of Fiction with a New Epilogue. Oxford UP, 2000.

Kincade, Kit. "Failures of the Patriarchy; Fathers as Role Models in Jane Austen." Jane Austen and Masculinity. Bucknell UP, 2017, pp. 41-60.

Kreisel, Deanna K. Demand, Gender, and Narrative Closure in Eliot and Hardy. Toronto UP, 2012.

Labovitz, Ester Kleinbord. The Myth of the Heroine; The Female Bildungsroman in the Twentieth Century. Second ed., Peter Lang Publishing, 1988.

Lazzaro-Weis, Carol. From Margins to Mainstream: Feminism and Fictional Modes in Italian Women's Writing, 1968-1990. Pennsylvania UP, 2011.

Leavis, F. R. The Great Tradition, 1948. Reissued, Pelican Books, 1972.

Livingston, Sally A. Marriage, Property, and Women's Narratives. Springer, 2012.

Lyons, Deborah. Dangerous Gifts: Gender and Exchange in Ancient Greece. Texas UP, 2012.

Makward, Christiane. "To Be or Not to Be . . . A Feminist Speaker.” Translated by Marlène Barsoum, Alice Jardine and Hester Eisenstein. The Future of Difference, edited by Hester Eisenstein and Alice Jardine. Hall, 1984, pp.95105.

Mathieson, Charlotte. “'Wandering Like a Wild Thing': Rurality, Women and Walking in George Eliot's Adam Bede and The Mill on the Floss." Gender and Space in Rural Britain, 1840-1920, edited by Gemma Goodman and Charlotte Mathieson, Pickering and Chatto, 2014, pp. 87-102.

McMaster. Juliet. Reading the Body in the Eighteenth-Century Novel. Springer, 2004.

---. "The Secret Languages of Emma." Persuasions: The Journal of the Jane Austen Society of North America, vol. 15, 1991, pp. 119-131.

Mill, John Stuart. "The Spirit of the Age.” The Spirit of the Age: Victorian Essays, edited by Gertrude Himmelfarb, Yale UP, 2007.

---. “The Subjection of Women." Edited by D. Appleton, ed. 4, Harvard UP, 1870. 
Miller, Andrew. "Lives Unled in Realist Fiction.” Representations, vol. 98, no. 1, pp. 118-134.

Miller, D. A. "Problems of Closure in the Traditional Novel." Essays on Time, Plot, Closure, and Frames, edited by Brian Richardson, Ohio State UP, 2002, pp. 272-281.

Miller, Elizabeth Carolyn. "Fixed Capital and the Flow; Water Power, Steam Power, and The Mill on the Floss." Ecological Form: Systems and Aesthetics in the Age of Empire, edited by Nathan Hensley and Philip Steer, Fordham UP, 2018, pp. 85-100.

Miller, Hillis J. Reading for Our Time. Edinburgh UP, 2012.

Miller, Nancy K. Subject to Change: Reading Feminist Writing. Columbia UP, 1988.

Mintz, Alan L. George Eliot \& the Novel of Vocation. Harvard UP, 1978.

Mitchell, Sherry L. "Saint Teresa and Dorothea Brooke: The Absent Road to Perfection in Middlemarch." Victorian Newsletter, no. 92, 1997, pp. 32-37.

Monaghan, David. "Introduction: Jane Austen as a Social Novelist." Jane Austen in a Social Context, edited by David Monaghan. Macmillan Press, 1981, pp. 1-8.

Monk, Leland. "Murder She Wrote; The Mystery of Jane Austen's Emma." Journal of Narrative Theory, vol. 20, no. 3, 1990, pp. 342-353.

Moretti, Franco. The Way of the World; The Bildungsroman in European Culture, New Edition, translated by Albert Sbragi. Verso, 2000.

Morris, Pam. Jane Austen, Virginia Woolf and Worldly Realism. Edinburgh UP, 2017.

Nandrea, Lorri G. "Difference and Repetition in Austen's Persuasion." Studies in the Novel, vol. 39, no. 1, 2007, pp. 48-64.

Obama, Michelle. Becoming. Penguin, 2018.

Osborne, Katherine Dunagan. "Inherited Emotions: George Eliot and the Politics of Heirlooms." Nineteenth-Century Literature, vol. 64, no. 4, 2010, pp. 465-493.

Parkins, Wendy. Mobility and Modernity in Women's Novels, 1850s-1930s; Women Moving Dangerously. Springer, 2008.

Pascoe, Judith. The Hummingbird Cabinet: A Rare and Curious History of Romantic Collectors. Cornell UP, 2006.

Pohl, Nicole. Women, Space and Utopia, 1600-1800. Ashgate Publishing, 2006.

Poovey, Mary. The Financial System in Nineteenth-Century Britain. Oxford 
UP, 2003.

Posusta, Rebecca. "Architecture of the Mind and Place in Jane Austen's Persuasion."

Critical Survey, vol. 26, no 1, 2014, pp. 76-91.

Pratt, Annis, et al. Archetypal Patterns in Women's Fictions. Indiana UP, 1981.

Ralph, Phyllis C. Transformations: Fairy Tales, Adolescence, and the Novel of

Female Development in Victorian Fiction. U of Kansas P, 1984.

Rignall, John. Oxford Readers Companion to George Eliot. Oxford UP, 2000.

Scott, Walter. Unsigned review of Emma. Quarterly Review 14 (October 1815):

188- 201, reprinted in Jane Austen; Critical Heritage Volume 11811 -

1870, edited by B.C. Southam, Routledge, 1995.

Shuttleworth, Sally. George Eliot and Nineteenth-Century Science; The Make

Believe of a Beginning, Cambridge UP, 1984.

Smith, David. "'In their death they were not divided:' The Form of Illicit Passion in The Mill on the Floss." Literature and Psychology, vol. 15, no. 3, 1965, pp. 144-162.

Spacks, Patricia Meyer. "Muted Discord: Generational Conflict in Jane Austen." Jane Austen in a Social Context, edited by David Monaghan, Macmillan, 1981, pp. 159-179.

Stafford, Fiona. "Persuasion: The Gradual Dawning." A Companion to Jane Austen, edited by Claudia L. Johnson and Clara Tuite, John Wiley and Sons, 2011, pp. 143-152.

Stovel, Bruce. "Subjective to Objective: A Career Pattern in Jane Austen, George Eliot, and Contemporary Women Novelists." Ariel, vol. 18, no. 1, 1987, pp. 53-61.

Sturrock, June. Jane Austen's Families. Anthem Press, 2013.

Tandon, Bharat. Jane Austen and the Morality of Conversation. Anthem, 2003.

Thaden, Barbara Z. The Maternal Voice in Victorian Fiction: Rewriting the Patriarchal Family. Routledge, 2013.

Torgovnick, Marianna. Closure in the Novel. Princeton UP, 2017.

Weinsheimer, Joel C. "In Praise of Mr. Woodhouse; Duty and Desire in Emma.” Ariel, vol. 6, no. 1, 1975, pp. 81.

Westkott, Maria. "Mothers and Daughters in the World of the Father." Frontiers: A Journal of Women Studies, vol. 3, no. 2, 1978, pp. 16-21.

Wiesenfarth, Joseph. “Middlemarch: The Language of Art.” PMLA, vol, 97, no, 3, 
1982, pp. 363-377.

Woolf, Virginia. “George Eliot.” The Common Reader, 1925. Seventh Impression, Hogarth, 1948.

Young, Kay. "Feeling Embodied: Consciousness, Persuasion, and Jane Austen." Narrative, vol. 11, no. 1, 2003, pp. 78-92.

Zimmerman, Bonnie. “George Eliot's Sacred Chest of Language.” Famous Last

Words: Changes in Gender and Narrative Closure, edited by Alison Booth, University of Virginia Press, 1993. 